University of Warwick institutional repository: http://go.warwick.ac.uk/wrap

This paper is made available online in accordance with publisher policies. Please scroll down to view the document itself. Please refer to the repository record for this item and our policy information available from the repository home page for further information.

To see the final version of this paper please visit the publisher's website. Access to the published version may require a subscription.

Author(s): Griffin XL, Smith N, Parsons N, Costa ML.

Article Title: Ultrasound and shockwave therapy for acute fractures in adults (Protocol)

Year of publication: 2012

Link to published article : http://dx.doi.org/10.1002/14651858.CD008579

Publisher statement: This review is published as a Cochrane Review in the Cochrane Database of Systematic Reviews 2012, Issue 2.

Cochrane Reviews are regularly updated as new evidence emerges and in response to comments and criticisms, and the Cochrane Database of Systematic Reviews should be consulted for the most recent version of the Review. Griffin, X.L., et al. (2012). Ultrasound and shockwave therapy for acute fractures in adults (protocol). Cochrane Database of Systematic Reviews, (7), Article CD008579. DOI:

10.1002/14651858.CD008579.pub2. 


\title{
Ultrasound and shockwave therapy for acute fractures in adults (Review)
}

\author{
Griffin XL, Smith N, Parsons N, Costa ML
}

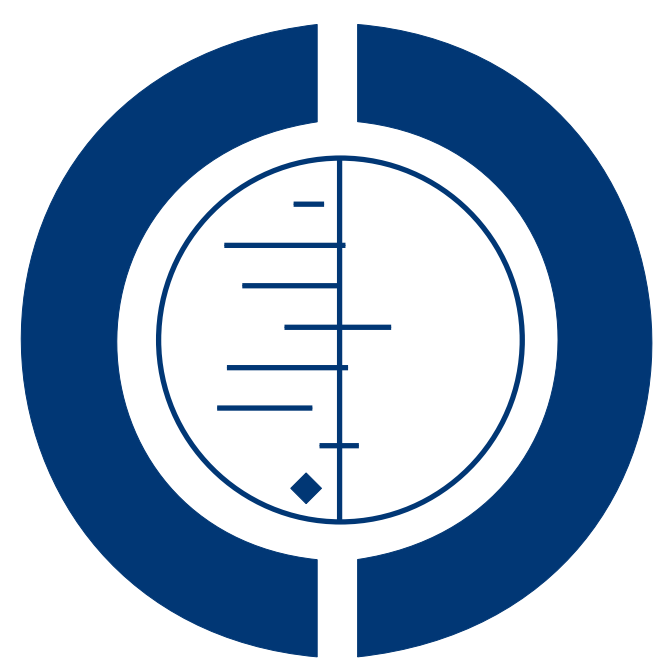

\section{THE COCHRANE COLLABORATION $^{\circledR}$}

This is a reprint of a Cochrane review, prepared and maintained by The Cochrane Collaboration and published in The Cochrane Library 2012, Issue 2

http://www.thecochranelibrary.com

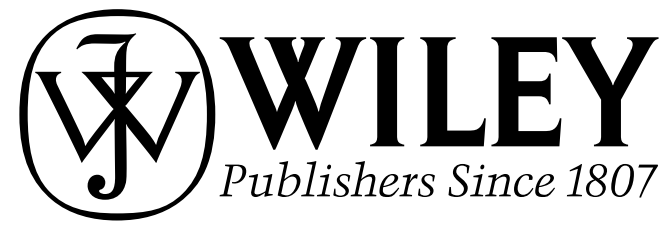

Ultrasound and shockwave therapy for acute fractures in adults (Review)

Copyright (C) 2012 The Cochrane Collaboration. Published by John Wiley \& Sons, Ltd. 
TABLE OF CONTENTS

HEADER . . . . . . . . . . . . . . . . . . . . . . . . . . . . . . . . . . . . . . 1

ABSTRACT . . . . . . . . . . . . . . . . . . . . . . . . . . . . . . . . . . . . . . . . . . . . 1

PLAIN LANGUAGE SUMMARY . . . . . . . . . . . . . . . . . . . . . . . . . . . . . . . . . . . . . $\quad . \quad 2$

BACKGROUND . . . . . . . . . . . . . . . . . . . . . . . . . . . . . . . . . . . . 3

OBJECTIVES . . . . . . . . . . . . . . . . . . . . . . . . . . . . . . . . . . . . . . 3

METHODS . . . . . . . . . . . . . . . . . . . . . . . . . . . . . . . . . . . . . . 3

RESULTS . . . . . . . . . . . . . . . . . . . . . . . . . . . . . . . . . . . . . . . 6

Figure 1. . . . . . . . . . . . . . . . . . . . . . . . . . . . . . . . . . . . . . 8

Figure 2. . . . . . . . . . . . . . . . . . . . . . . . . . . . . . . . . . . . . . 10

Figure 3. . . . . . . . . . . . . . . . . . . . . . . . . . . . . . . . . . . . . . 11

Figure 4. . . . . . . . . . . . . . . . . . . . . . . . . . . . . . . . . . . . . . 12

Figure 5. . . . . . . . . . . . . . . . . . . . . . . . . . . . . . . 13

DISCUSSION . . . . . . . . . . . . . . . . . . . . . . . . . . . . . . . . 14

AUTHORS' CONCLUSIONS . . . . . . . . . . . . . . . . . . . . . . . . . . . . . . . . . . . . . 16

ACKNOWLEDGEMENTS . . . . . . . . . . . . . . . . . . . . . . . . . . . . . . . . . . . . . . . . . .

REFERENCES . . . . . . . . . . . . . . . . . . . . . . . . . . . . . . . . . . . . . 17

CHARACTERISTICS OF STUDIES . . . . . . . . . . . . . . . . . . . . . . . . . . . . . . . . . . . 19

DATA AND ANALYSES . . . . . . . . . . . . . . . . . . . . . . . . . . . . . . . . . . . . . . . . . . . . . . 41

Analysis 1.1. Comparison 1 LIPUS versus control, Outcome 1 Time to return to work complete fractures (days). . . 42

Analysis 1.2. Comparison 1 LIPUS versus control, Outcome 2 Time to return to training / duty after stress fracture (days): as reported analysis (days). . . . . . . . . . . . . . . . . . . . . . . . . . . . . .

Analysis 1.3. Comparison 1 LIPUS versus control, Outcome 3 Time to fracture radiographic union (days): 'as reported' analysis.

Analysis 1.4. Comparison 1 LIPUS versus control, Outcome 4 Time to fracture radiographic union (days): worst case analysis.

Analysis 1.5. Comparison 1 LIPUS versus control, Outcome 5 Time to fracture union (days) subgrouped by operation: worst case analysis.

Analysis 1.6. Comparison 1 LIPUS versus control, Outcome 6 Time to fracture union (days) subgrouped by smoking status: worst case analysis. . . . . . . . . . . . . . . . . . . . . . . . . . . . . . . 47

Analysis 1.7. Comparison 1 LIPUS versus control, Outcome 7 Delayed or non-union (as reported analysis). $\quad . \quad$. $\quad . \quad 48$

Analysis 1.8. Comparison 1 LIPUS versus control, Outcome 8 Pain at 8 weeks (VAS: 0 no pain to 10 worst pain). $\quad 49$

Analysis 2.1. Comparison 2 ECSW versus control, Outcome 1 Non-union at 12 months follow-up. . . . . . . . $\quad 49$

Analysis 2.2. Comparison 2 ECSW versus control, Outcome 2 Pain at 3 months (VAS: 0 no pain to 10 severe pain). 50

APPENDICES . . . . . . . . . . . . . . . . . . . . . . . . . . . . . . . . . . . . . 50

HISTORY . . . . . . . . . . . . . . . . . . . . . . . . . . . . . . . . . . . . . . . 52

CONTRIBUTIONS OF AUTHORS . . . . . . . . . . . . . . . . . . . . . . . . . . . . . . . . 52

DECLARATIONS OF INTEREST . . . . . . . . . . . . . . . . . . . . . . . . . . . . . . . . . . 52

SOURCES OF SUPPORT . . . . . . . . . . . . . . . . . . . . . . . . . . . . . . . . . . . . . . . . . 52

DIFFERENCES BETWEEN PROTOCOL AND REVIEW . . . . . . . . . . . . . . . . . . . . . . . . . 53

Ultrasound and shockwave therapy for acute fractures in adults (Review)

Copyright $(2012$ The Cochrane Collaboration. Published by John Wiley \& Sons, Ltd. 


\title{
[Intervention Review]
}

\section{Ultrasound and shockwave therapy for acute fractures in adults}

\author{
Xavier L Griffin ${ }^{1}$, Nick Smith ${ }^{1}$, Nick Parsons ${ }^{1}$, Matthew L Costa ${ }^{1}$ \\ ${ }^{1}$ Warwick Orthopaedics, Warwick Medical School, University of Warwick, Coventry, UK \\ Contact address: Xavier L Griffin, Warwick Orthopaedics, Warwick Medical School, University of Warwick, Clinical Sciences Building, \\ Clifford Bridge Road, Coventry, CV2 2DX, UK. x.griffin@warwick.ac.uk. xgriffin@mac.com.
}

Editorial group: Cochrane Bone, Joint and Muscle Trauma Group.

Publication status and date: New, published in Issue 2, 2012.

Review content assessed as up-to-date: 12 December 2011.

Citation: Griffin XL, Smith N, Parsons N, Costa ML. Ultrasound and shockwave therapy for acute fractures in adults. Cochrane Database of Systematic Reviews 2012, Issue 2. Art. No.: CD008579. DOI: 10.1002/14651858.CD008579.pub2.

Copyright (C) 2012 The Cochrane Collaboration. Published by John Wiley \& Sons, Ltd.

\begin{abstract}
A B S T R A C T
Background

The morbidity and socioeconomic costs of fractures are considerable. The length of time to healing is an important factor in determining a patient's recovery after a fracture. Ultrasound may have a therapeutic role in reducing the time to union after fracture.
\end{abstract}

\section{Objectives}

To assess the effects of low intensity ultrasound (LIPUS), high intensity focused ultrasound (HIFUS) and extracorporeal shockwave therapies (ECSW) as part of the treatment of acute fractures in adults.

\section{Search methods}

We searched the Cochrane Bone, Joint and Muscle Trauma Group Specialised Register (December 2011), the Cochrane Central Register of Controlled Trials (in The Cochrane Library 2011, Issue 4), MEDLINE (1950 to November Week 3 2011), EMBASE (1980 to 2011 Week 49), trial registers and reference lists of articles.

\section{Selection criteria}

Randomised controlled trials evaluating ultrasound treatment in the management of acute fractures in adults. Studies including participants over 18 years of age with acute fractures, reporting functional outcomes, time to union, non-union, secondary procedures such as for fixation or delayed or non-union, adverse effects, pain, costs or patient adherence were included.

\section{Data collection and analysis}

Two authors independently extracted data from the included studies. Treatment effects were assessed using mean differences or risk ratios and, where there was substantial heterogeneity, pooled using a random-effects model. Results from 'worst case' analyses, which gave more conservative estimates of treatment effects for time to fracture union, are reported in preference to those from 'as reported' analyses.

\section{Main results}

Twelve studies, involving 622 participants with 648 fractures, were included. Eight studies were randomised placebo-controlled trials, two studies were randomised controlled trials without placebo controls, one study was a quasi-randomised placebo controlled trial and the remaining study was a quasi-randomised controlled trial without placebo control. Eleven trials tested LIPUS and one trial tested 
ECSW. Four trials included participants with conservatively treated upper limb complete fractures and six trials included participants with lower limb complete fractures; these were surgically fixed in four trials. The remaining two trials reported results for conservatively treated tibial stress fractures.

Very limited data from two complete fracture studies showed no difference between ultrasound and placebo control in functional outcome. Pooled estimates from two studies found LIPUS did not significantly affect the time to return to training or duty in soldiers or midshipmen with stress fractures (mean difference -8.55 days, $95 \%$ CI -22.71 to 5.61 ).

Based on a 'worst case' analysis, which adjusted for incomplete data, pooled results from eight heterogeneous studies showed no statistically significant reduction in time to union of complete fractures treated with LIPUS (standardised mean difference $-0.47,95 \%$ CI -1.14 to 0.20 ). This result could include a clinically important benefit or harm, and should be seen in the context of the highly significant statistical heterogeneity $\left(\mathrm{I}^{2}=90 \%\right)$. This heterogeneity was not explained by the a priori subgroup analyses (upper limb versus lower limb fracture, smoking status). An additional subgroup analysis comparing conservatively and operatively treated fractures raised the possibility that LIPUS may be effective in reducing healing time in conservatively managed fractures, but the test for subgroup differences did not confirm a significant difference between the subgroups.

Pooled results from eight trials reporting proportion of delayed union or non-union showed no significant difference between LIPUS and control. Adverse effects directly associated with LIPUS and associated devices were found to be few and minor, and compliance with treatment was generally good. One study reporting on pain scores found no difference between groups at eight weeks.

One quasi-randomised study (59 fractures) found no significant difference between ECSW and no-placebo control groups in nonunion at 12 months (risk ratio $0.56,95 \%$ CI 0.15 to 2.01 ). There was a clinically small but statistically significant difference in the visual analogue scores for pain in favour of ECSW at three month follow-up. The only reported complication was infection, with no significant difference between the two groups.

\section{Authors' conclusions}

While a potential benefit of ultrasound for the treatment of acute fractures in adults cannot be ruled out, the currently available evidence from a set of clinically heterogeneous trials is insufficient to support the routine use of this intervention in clinical practice. Future trials should record functional outcomes and follow-up all trial participants.

\section{PLAIN LANGUAGE SUMMARY}

\section{Does ultrasound treatment of broken bones in adults help improve bone healing times and reduce complications?}

Broken bones (fractures) are a major cause of disability in adults. The time taken for a bone to heal (achieve "union") is an important factor in determining recovery after an injury. A minority of fractures fail to heal at all or in an appropriate period of time. This review set out to find out whether treatment with ultrasound, in a variety of forms, accelerates fracture healing and reduces complications associated with fresh (acute) fractures. A related intervention, shockwave therapy, was also examined. Typically, ultrasound treatment involves placing a special device in contact with the skin overlying the fracture site for around 20 minutes on a daily basis.

Twelve studies, involving 622 participants with 648 fractures, were included in this review. Most participants had suffered a fresh complete fracture of a single bone. The participants of two trials had incomplete or stress fractures, resulting from heavy exercise. Four trials tested the effects of ultrasound on healing of upper limb fractures and the other trials, on lower limb fractures. The most commonly investigated bone was the tibia (shin bone). Eleven trials tested low intensity pulsed ultrasound and one trial tested shockwave therapy.

Most trials compared a working ultrasound device with a sham device and thus protected against placebo effects. However, the results of many trials were probably biased because of missing data from several trial participants. Additionally, the trials were very varied; for example, in the bone that was broken and that some fractures were treated surgically. Based on analyses that adjusted for these missing data, the review found that the available evidence did not confirm that ultrasound speeded up bone healing or prevented non-union. The results from one low quality trial testing shockwave therapy were inconclusive. Few complications were reported and these were not related to the ultrasound or shockwave therapy. 


\section{B A C K G R O U N D}

\section{Description of the condition}

The morbidity and socioeconomic cost of fractures (broken bones) is considerable. Whilst most fractures unite, between $5 \%$ and $10 \%$ of long bone fractures are associated with delayed or non-union, resulting in significant morbidity, loss of independence and loss of productivity (Aaron 2004). The length of time to healing is also an important factor in determining recovery after a fracture (Heckman 1997). Several interventions, including ultrasound, have been proposed to enhance and accelerate bone healing, and potentially reduce the incidence of the complications associated with fractures and their treatment (Einhorn 1995; Hadjiargyrou 1998).

\section{Description of the intervention}

Ultrasound, comprising high frequency sound waves, is a form of mechanical stimulation that is delivered via a special device to the fracture site. For closed fractures (where the overlying soft tissue envelope remains intact), the device is typically placed in contact with the skin overlying the fracture site and left in position for around 20 minutes on a daily basis.

There are three modalities of ultrasound used in clinical practice:

- Low intensity pulsed ultrasound (LIPUS)

- High intensity focused ultrasound (HIFUS)

- Extracorporeal shock wave therapy (ECSW)

\section{How the intervention might work}

It is known that bone formation and fracture healing are influenced by mechanical factors. It is possible that ultrasound might work by reproducing the effect of functional loading by inducing low level mechanical forces at the fracture site. The mechanisms have not been fully elucidated (Hadjiargyrou 1998) but it is likely that ultrasound influences healing at multiple points during the fracture healing process.

Although it is thought that all three ultrasound modalities work in a similar way in the body, the effectiveness of each modality does appear to be different (Reher 1997; Wang 1994). Thus, these three modalities will be considered separately in this review.

\section{Why it is important to do this review}

The ability to improve fracture healing would have a large clinical and socioeconomic impact. Whilst there is currently no consensus on the role of ultrasound, its use is becoming increasingly widespread (Victoria 2009). A recent systematic review has identified a broad evidence base concerning the use of ultrasound in the management of acute fractures (Griffin 2008). This review updates the summary of the available best evidence on the use of ultrasound for acute fractures in order to inform practice and highlight areas in need of further research.

\section{O B J E C T I VES}

To assess the effects of any ultrasound therapy used as part of the treatment of acute fractures in adults.

We planned to make the following comparisons:

1. Low intensity pulsed ultrasound (LIPUS) versus control (sham ultrasound or none)

2. High intensity focused ultrasound (HIFUS) versus control (sham ultrasound or none)

3. Extracorporeal shockwave therapy (ECSW) versus control (sham ultrasound or none)

Participants might additionally receive a standard-of-care treatment which would be the definitive treatment routinely used in clinical practice for the treatment of the fracture. This might include, but not be limited to, non-surgical treatment, such as plaster cast immobilisation, or surgical treatment such as external or internal fixation, using various devices such as intramedullary nailing.

\section{METHODS}

\section{Criteria for considering studies for this review}

\section{Types of studies}

Randomised and quasi-randomised (a method of allocating participants to a treatment which was not strictly random; e.g. by date of birth, hospital record number, alternation) controlled clinical studies evaluating any type of ultrasound treatment in the management of acute fractures in adults.

\section{Types of participants}

Any skeletally mature adults, over the age of 18 years, with acute fractures. Trials evaluating treatment for delayed or non-union were excluded. 


\section{Types of interventions}

Trials of all three types of ultrasound (low intensity pulsed ultrasound (LIPUS), high intensity focused ultrasound (HIPUS), and extracorporeal shock wave therapy (ECSW)) were eligible provided the treatment was compared with either no additional treatment or a placebo (sham ultrasound). Ultrasound could be the only treatment, but would more usually be an adjunct to a standard-of-care treatment applied to all trial participants. The standard-of-care treatment could be non-surgical or surgical. Trials comparing ultrasound with other interventions were excluded. Each modality of ultrasound treatment was considered in a separate comparison as described in the Objectives.

\section{Types of outcome measures}

Functional recovery, including return to former activities, was the prime focus of the review. However, we anticipated that most trials would not report patient-reported outcome measures but would focus instead on fracture healing outcomes.

The definition of a healed fracture is contentious. For the purpose of this review we adopted the widely accepted definitions in the literature. A fracture is healed when callus is present bridging three of four cortices on orthogonal radiographs or there is an absence of pain and movement at the fracture site or both. It was expected that most studies would report the time to union for each participant. These are the most frequently reported statistics when studies are published in this field. However, it was possible that some studies might have presented a proportional analysis of healed fractures at a number of fixed time points after treatment.

\section{Primary outcomes}

The primary outcomes assessed were:

- Overall quantitative functional improvement of the participant using recognised patient-reported outcome measures and the return to normal activities, including work

- Time to fracture union

\section{Secondary outcomes}

The secondary outcomes assessed were:

- Confirmed non-union or secondary procedure, such as for failure of fixation or for delayed or non-union

- Adverse effects

- Pain using validated pain scores

- Costs

- Patient adherence

\section{Timing of outcome assessment}

We anticipated that some studies might have reported proportional incidence of union at several time points rather than a time- to-event analysis. We planned to try to group these assessments into three categories: short (up to three months), medium (between three and twelve months) and long-term follow-up (greater than one year) (see Unit of analysis issues). These time points were a necessary compromise to encompass data from studies which included different bones with different typical healing times.

\section{Search methods for identification of studies}

\section{Electronic searches}

We searched the Cochrane Bone, Joint and Muscle Trauma Group Specialised Register (December 2011), the Cochrane Central Register of Controlled Trials (The Cochrane Library 2011, Issue 4), MEDLINE (1950 to November Week 3 2011) and EMBASE (1980 to 2011 Week 49). There were no constraints based on language or publication status.

In MEDLINE, the subject-specific search was combined with the Cochrane Highly Sensitive Search Strategy for identifying randomised trials: sensitivity-maximising version (Lefebvre 2009). In EMBASE, the subject-specific search was combined with the SIGN strategy for randomised controlled trials (see Appendix 1 for all strategies).

Current Controlled Trials and the WHO International Clinical Trials Registry Platform were also searched in order to identify ongoing and recently completed trials.

\section{Searching other resources}

We searched reference lists of articles retrieved from the electronic search. We contacted experts in the field for any additional or unpublished articles.

\section{Data collection and analysis}

\section{Selection of studies}

Two authors (XG and NS) independently selected the studies for inclusion in the review based upon the criteria defined above. Initially the titles and abstracts of all the retrieved studies were reviewed to determine potential eligibility. The full text of each study in this shortlist was then reviewed to determine which studies were eligible for inclusion in the review. Any disagreement was settled by consensus between all authors of the review. 


\section{Data extraction and management}

Two authors (XG and NS) independently extracted data from the included studies using a pre-piloted version of the Cochrane Bone, Joint and Muscle Trauma Group's data extraction form. The review statistician (NP), who was independent from study selection, collated and processed the extracted outcome data.

\section{Assessment of risk of bias in included studies}

The included studies were each assessed for the risk of bias using The Cochrane Collaboration's 'Risk of bias' tool (Higgins 2008). This tool incorporates assessment of randomisation (sequence generation and allocation concealment), blinding (trial participants and personnel, and outcome assessors), completeness of outcome data, selection of outcomes reported and other sources of bias. Other sources of bias included selection bias, where we assessed the risk of bias from imbalances in key baseline characteristics (age, sex and smoking behaviour). We assessed the risk of bias associated with a) blinding and b) completeness of outcomes for patient-reported outcomes and objective outcomes separately. Different considerations apply to the primary outcome of fracture healing, which is variably defined in the literature. We anticipated that studies may define healing clinically and radiographically. We anticipated that bias might be introduced by inter and intra-observer error in the reading of radiographs. We ascribed a low risk to studies in which a blinded panel of specialist radiologists or orthopaedic surgeons read the radiographs. Studies employing other methodologies, such as multiple independent observers, were ascribed a high risk of bias.

\section{Measures of treatment effect}

We had intended to assess time to fracture union after treatment using a $(\log )$ hazard ratio and $95 \%$ confidence intervals. However, as we had anticipated, fracture union was either reported as a proportion of fractures healed at each follow-up time-point, or the mean time to union. Where studies reported a proportion of fractures healed we calculated the mean time to union (and standard deviation) assuming that each fracture had healed at the end of the interval between follow-up time-points. From the reported and calculated mean times to union we calculated standardised mean differences and $95 \%$ confidence intervals. This reflected the widely differing mean times to union in different studies including different bones. Risk ratios with $95 \%$ confidence intervals were used to express the intervention effect for dichotomous outcomes. For continuous data, such as pain scores, we calculated mean differences with $95 \%$ confidence intervals.

\section{Unit of analysis issues}

It was expected that most studies would report functional improvement scores at a number of follow-up times; for example, at six and twelve weeks. Dependent on the nature of reporting, separate analyses were to be made at each of the commonly reported occasions, representing perhaps, short, medium and long-term followup. It was expected that all studies would report simple parallel group designs. However, if other designs were reported (e.g. cluster randomised designs) generic inverse variance methods were to be used to combine data where appropriate.

\section{Dealing with missing data}

We sought additional information from the authors of the included studies where the published information or data were incomplete. Where standard deviations were not specifically reported, we attempted to determine these, if available, from standard errors, confidence intervals or exact $\mathrm{P}$ values. We did not expect there to be substantial missing data for studies in this research area. Where small amounts of data were missing for proportional outcomes, that could not be reliably determined from the authors, then these outcomes were initially classed as treatment failures and a sensitivity analysis conducted to test the effect of this assumption. For continuous measures, in order to determine a conservative estimate of any treatment effect, we assumed that healing times of participants in the treatment group for whom data were missing lay at the extreme of the distribution (two standard deviations from the reported mean). Conversely, for participants in the control group we assumed the distribution was unaffected by the missing data. Pooled effect sizes were presented with and without these adjustments to check the effect of these assumptions. We refer to the adjusted analyses as 'worst case' analyses and the unadjusted as 'as reported' analyses.

\section{Assessment of heterogeneity}

The degree of statistical heterogeneity between studies was assessed graphically using the $\mathrm{Chi}^{2}$ test and $\mathrm{I}^{2}$ statistic (Higgins 2003). A conservative $\mathrm{P}$ value for $\mathrm{Chi}^{2}$ of $<0.1$ was set to indicate significant heterogeneity between studies. If the heterogeneity statistic indicated significant heterogeneity and one or more studies appeared to be clear outliers, then data for these studies would be checked carefully for errors or other methodological reasons why they might differ from the other studies. We planned that if good reason was found why the studies differed from the majority then this would be noted and reported and the studies removed from the main meta-analyses; however all analyses would be performed with and without outlier studies in the event that any were excluded (sensitivity analysis).

\section{Assessment of reporting biases}

Our search strategy attempted to reduce the risk of missing relevant studies. We planned to complete a funnel plot if a sufficient number of studies had been available. 


\section{Data synthesis}

Treatment effects from studies reporting proportional outcomes were summarised using risk ratios and combined using the MantelHaenszel method. Continuous outcome measures were converted to standardised mean differences to assess the treatment effect and generic inverse variance methods were used to combine data. Confidence intervals were reported at the $95 \%$ level and initially the fixed-effect model was used for meta-analyses. Where there was significant heterogeneity, we used the random-effects model.

\section{Subgroup analysis and investigation of heterogeneity}

We planned to conduct subgroup analysis to explore possible sources of heterogeneity when significant heterogeneity was present. Two possible subgroup analyses were identified a priori:

1. Upper versus lower limb fractures. This was a pragmatic proxy for weight bearing versus non-weight bearing bones.

2. Smokers versus non-smokers.

\section{Sensitivity analysis}

We conducted post hoc sensitivity analyses to explore the causes of statistical heterogeneity. We also explored the effect of excluding studies because they appeared to differ markedly from the majority of studies. For each of these analyses, a pooled estimate of the effect size was reported with and without these studies.

\section{R E S U L T S}

\section{Description of studies}

See: Characteristics of included studies; Characteristics of excluded studies; Characteristics of studies awaiting classification; Characteristics of ongoing studies.

\section{Results of the search}

A total of 954 references were retrieved using the search strategy. Thirty-six references were thought to be relevant after screening the abstracts and the full text article was retrieved for each. Some of these references were reports of the same study. From these, 12 studies were included in the review and three were excluded. Searches of study reference lists, trials registers and contact with experts, revealed three further studies, one of which is ongoing (see Characteristics of ongoing studies), and two, one of which was located after the main search, are awaiting assessment (see Studies awaiting classification).

\section{Included studies}

Twelve studies, involving 622 participants with 648 fractures, were included in the review. Details of the individual studies are shown in the Characteristics of included studies.

\section{Design}

Eight studies were randomised placebo-controlled trials and two studies (Mayr 2000; Strauss 1999) were randomised controlled trials without placebo controls. Of the two quasi-randomised studies, one was placebo-controlled (Leung 2004) and the other (Wang 2007) was not.

Cook 1997 reported a subgroup analysis by smoking status of participants recruited in the trials reported by Heckman 1994 and Kristiansen 1997. These data were not doubly entered into the analyses but have been used to inform an a priori subgroup analysis in this review.

\section{Sample sizes}

Each of the included studies included relatively few participants:

- Emami 1999: 30 participants (15:15, ultrasound:control).

- Handolin 2005: 30 participants (15:15, ultrasound: control).

- Handolin 2005a: 22 participants (11:11, ultrasound: control).

- Heckman 1994: 97 participants (48:49, ultrasound: control).

- Kristiansen 1997: 85 fractures in 83 participants (40:45, ultrasound:control).

- Leung 2004: 30 fractures in 28 participants (16:14, ultrasound:control).

- Lubbert 2008: 120 participants (61:59 ultrasound:control).

- Mayr 2000: 30 fractures in 29 participants (15:15, ultrasound:control).

- Rue 2004: 58 fractures in 40 participants (21:19, ultrasound:control).

- Strauss 1999: 20 participants (10:10, ultrasound:control).

- Wang 2007: 59 fractures in 56 participants (28:31, ECSW: control).

- Yadav 2008: 67 participants (39:28, ultrasound:control).

\section{Settings}

The studies that reported outcomes in participants with complete fractures were set in hospital Trauma and Orthopaedic Departments. These studies were based in a wide variety of countries: Sweden (Emami 1999), Finland (Handolin 2005; Handolin 2005a), USA (Heckman 1994; Kristiansen 1997; Strauss 1999), China (Leung 2004), Netherlands (Lubbert 2008), Germany (Mayr 2000) and Taiwan (Wang 2007). The study reported by Kristiansen 1997 was a multi-centre study. Rue 2004 reported 
outcomes in American midshipmen with stress fractures presenting to a military clinic. Yadav 2008 reported outcomes in Indian soldiers with stress fractures presenting to a military clinic.

\section{Participants}

The majority of studies reported outcomes from participants with conservatively managed fresh fractures; of these, Heckman 1994 reported data from fractures of the tibia, Strauss 1999 fractures of the fifth metatarsal, and the remainder from upper limb fractures (Kristiansen 1997: distal radius; Lubbert 2008: clavicle; Mayr 2000: scaphoid). Three studies reported outcomes from participants with operatively managed fractures of the tibia (Emami 1999; Leung 2004) or tibia and femur (Wang 2007), and two reported results from participants following internal fixation of lateral malleolus (ankle) fractures (Handolin 2005; Handolin 2005a).

Two studies reported outcomes from participants with acute stress fractures of the tibia (Rue 2004; Yadav 2008).

\section{Interventions}

All the included studies reported the use of LIPUS except Wang 2007, which tested ECSW therapy. The nine placebo-controlled LIPUS trials used a sham ultrasound machine, which was deactivated.

The LIPUS treatments were very similar across the included studies. Participants given the test treatment received ultrasound treatment for 20 minutes each day for a total cumulative time of approximately 24 hours. The ultrasound signal was composed of a $200 \mu$ surst of $1.5 \mathrm{MHz}$ sine waves, with a repetition rate of 1 $\mathrm{kHz}$ and a spatial average intensity of $30 \mathrm{~mW} / \mathrm{cm}^{2}$.

All 10 studies of participants with complete fractures reported the effectiveness of the test treatment in addition to a method of bony stabilisation. In five studies, stabilisation was achieved with either a plaster or a brace (Heckman 1994; Kristiansen 1997; Lubbert 2008; Mayr 2000; Strauss 1999). Internal fixation was used in the remaining studies (Emami 1999; Handolin 2005; Handolin 2005a; Leung 2004; Wang 2007).

\section{Outcomes}

A mixture of outcomes was reported. The majority of studies reported time to radiographic union using plain radiographs as the primary measure of efficacy (Emami 1999; Handolin 2005a; Heckman 1994; Leung 2004). Mayr 2000 used computed tomography to determine fracture union. Each of these studies measured union at multiple time points at various intervals (related to fracture site) from which mean time to union was derived. Wang 2007 and Strauss 1999 reported the proportion of radiographic union only. Handolin 2005, Lubbert 2008, Rue 2004 and Yadav 2008 presented patient-reported outcomes: a region-specific functional score, subjective fracture union and return to work (Rue 2004 and Yadav 2008) respectively.

\section{Excluded studies}

The reasons for exclusion of three studies are detailed in the Characteristics of excluded studies. Two studies reporting on costs were excluded because the data for the economic analysis were not obtained from a randomised trial (Busse 2005; Heckman 1997). Basso 1998, a quasi-randomised trial, did not focus on fracture healing nor report relevant outcomes to this review.

\section{Risk of bias in included studies}

The quality of reporting of the studies was varied. A summary of the assessment of the risk of bias in each study can be found in Figure 1 
Figure I. Risk of bias summary: review authors' judgements about each risk of bias item for each included study.

\begin{tabular}{|c|c|c|c|c|c|c|c|c|c|}
\hline & 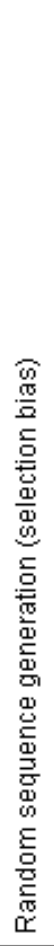 & 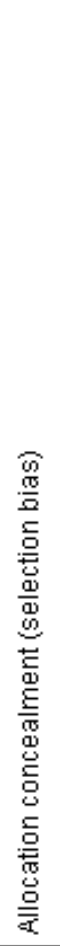 & 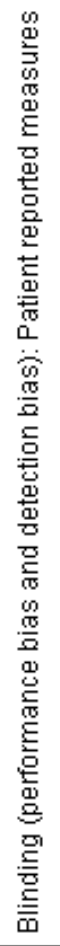 & 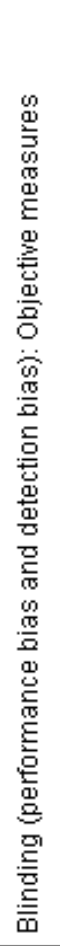 & 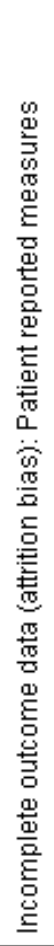 & 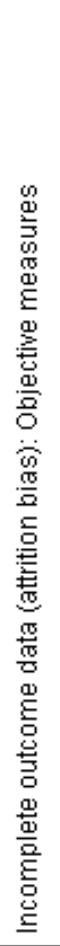 & 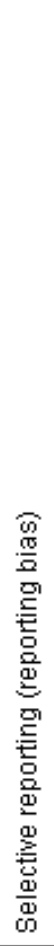 & 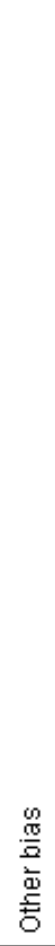 & 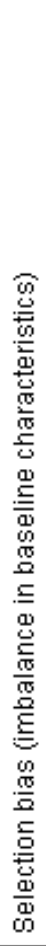 \\
\hline Emami 1999 & $?$ & $?$ & + & $\odot$ & + & $?$ & $?$ & - & + \\
\hline Handolin 2005 & $?$ & ? & + & + & + & - & $?$ & $?$ & $?$ \\
\hline Handolin 2005a & $?$ & + & + & $?$ & + & $\odot$ & $?$ & + & $?$ \\
\hline Heckman 1994 & + & + & + & + & + & $?$ & $?$ & C & $?$ \\
\hline Kristiansen 1997 & $\odot$ & $?$ & + & + & + & - & $?$ & - & ? \\
\hline Leung 2004 & & ค & + & & + & $\odot$ & $?$ & - & $?$ \\
\hline Lubbert 2008 & + & + & + & $\odot$ & & $\odot$ & $?$ & + & $?$ \\
\hline Mayr 2000 & $\odot$ & $?$ & $?$ & $\odot$ & $?$ & $\odot$ & $?$ & + & $?$ \\
\hline Rue 2004 & $?$ & $?$ & + & $?$ & & - & $?$ & + & ? \\
\hline Strauss 1999 & $?$ & $?$ & $?$ & & + & $?$ & $?$ & 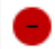 & $?$ \\
\hline Wang 2007 & & - & $?$ & $\odot$ & & - & $?$ & + & $?$ \\
\hline Yadav 2008 & + & $?$ & + & + & + & $\odot$ & $?$ & + & ? \\
\hline
\end{tabular}




\section{Allocation}

The majority of studies were randomised, although the sequence generation and methods of allocation were frequently poorly reported. Only two studies (Heckman 1994; Lubbert 2008) were rated at low risk of selection bias. The two quasi-randomised studies (Leung 2004; Wang 2007) were considered as being at high risk of selection bias.

\section{Blinding}

The majority of studies used a deactivated ultrasound unit to blind the allocation. However, the unit used by Leung 2004 was externally dissimilar to the intervention unit and therefore the blinding in this study may have been compromised. Three studies (Mayr 2000; Strauss 1999; Wang 2007) were not placebo-controlled. However, blinded outcome assessment was reported in Wang 2007.

\section{Incomplete outcome data}

None of the included studies explicitly reported, or justified where absent, all of the outcome data. We were successful in contacting authors of three trials (Heckman 1994; Kristiansen 1997; Lubbert 2008) for missing data. In general the proportion of missing data was sufficiently low, so that 'as reported' and 'worst case' analyses were similar. We judged three studies at high risk of attrition bias: Handolin 2005a because of the high (47\%) and unaccounted loss to follow-up at 18 months follow-up; Rue 2004 because of a high and attrition rate $(35 \%)$, in part resulting from post-hoc selection decision to limit their analysis to tibial stress fractures; and Wang 2007 because of inappropriate handling of participants with adverse events.

\section{Selective reporting}

The overall quality of the reporting of the included studies was poor. No protocols were available for comparing with the trial reports. The reporting of the methods and results was frequently mixed so that determining the risk of bias from selective reporting of outcomes was very difficult. However, there was no clear evidence of selective outcome reporting.

\section{Other potential sources of bias}

It was clear from all of the studies that, for obvious practical reasons, it was impossible to assess healing in each participant every day. Typically, participants were assessed at fixed follow-up intervals that varied between studies. This inevitably led to a lack of precision in estimates of healing times. However, we see no reason why this process should have differed between treatment groups in any study, so would not expect there to be any bias in estimates of the treatment effects. However, this may, at least in part, explain the significant heterogeneity in observed healing times between studies.

There were often insufficient data, in particular relating to smoking status, to judge whether there were major imbalances between the treatment and control groups in baseline characteristics. Only Emami 1999 was considered at low risk for this item.

\section{Effects of interventions}

\section{Low intensity pulsed ultrasound versus control}

\section{Primary outcomes}

\section{Functional outcomes}

\section{Complete fractures}

Only Lubbert 2008 provided data for return to work. There was no significant difference between the treatment and control groups using either 'as reported' data (mean difference (MD) 1.95 days, $95 \%$ CI -2.18 to 6.08 days) or when based upon a 'worst case' analysis (MD 1.42 days, 95\% CI -2.40 to 5.24) (see Analysis 1.1). Handolin 2005 reported no significant difference in the OlerudMolander score between treatment and control groups in 16 participants (53\% of the 30 randomised participants) at 18 months follow-up. However, insufficient data were reported to be able to confirm this report and efforts to contact the authors were unsuccessful.

\section{Stress fractures}

Rue 2004 and Yadav 2008 both reported time to the return to training or duty in midshipmen and military recruits respectively. There was no significant benefit of LIPUS in the treatment of stress fractures of the tibia using 'as reported' data (MD -8.55 days, 95\% CI -22.71 to 5.61) (see Analysis 1.2). There were insufficient baseline data from Rue 2004 to conduct a 'worst-case scenario' analysis. There was considerable heterogeneity in the pooled estimate $\left(\mathrm{I}^{2}=78 \%\right)$; the difference in the findings of the two trials is also clearly visible in the analysis. 


\section{Time to union}

Although time to union data were available in most studies, the definition of union, timing of assessment and statistical analysis were variable. Efforts made to contact authors from each study in order to carry out appropriate intention-to-treat analyses were partly successful.

Four studies defined union radiographically (Emami 1999; Handolin 2005a; Kristiansen 1997; Mayr 2000). Where data were presented from surgeons and radiologists, we report only those based upon radiologists' opinions. Three studies defined union as a combined clinical and radiographic finding with similar definitions of radiographic union (Heckman 1994; Kristiansen 1997; Leung 2004). Lubbert 2008 defined union based upon participants' self-reports.

Each of the studies reporting this outcome only reported a perprotocol analysis, where the reported data are for those partici- pants who complied with the protocol, including follow-up. These 'as reported' data are presented in Figure 2 (Analysis 1.3). Those authors who were successfully contacted explained that such an analysis was necessary because the data were missing due to the haphazard follow-up of some participants. This 'as reported' analysis demonstrated a significant benefit from LIPUS therapy (standardised mean difference (SMD) $-0.69,95 \%$ CI -1.31 to -0.07). However, the highly significant and substantial heterogeneity overall and for the upper and lower limb subgroups is also evident $\left(\mathrm{P}<0.00001 ; \mathrm{I}^{2}=86 \%\right)$. A conservative, or 'worst case' analysis, which attempted to include the missing data is presented in Figure 3 (Analysis 1.4; details of the imputation method described in Dealing with missing data), shows no significant difference between the treatment and control groups (SMD - 0.47 ; 95\% CI 1.14 to 0.20 ). The subgroup analysis by upper and lower limb fracture location did not significantly alter this finding.

Figure 2. Forest plot of comparison: I LIPUS versus control, outcome: I.3 Time to fracture radiographic union (days): 'as reported' analysis.

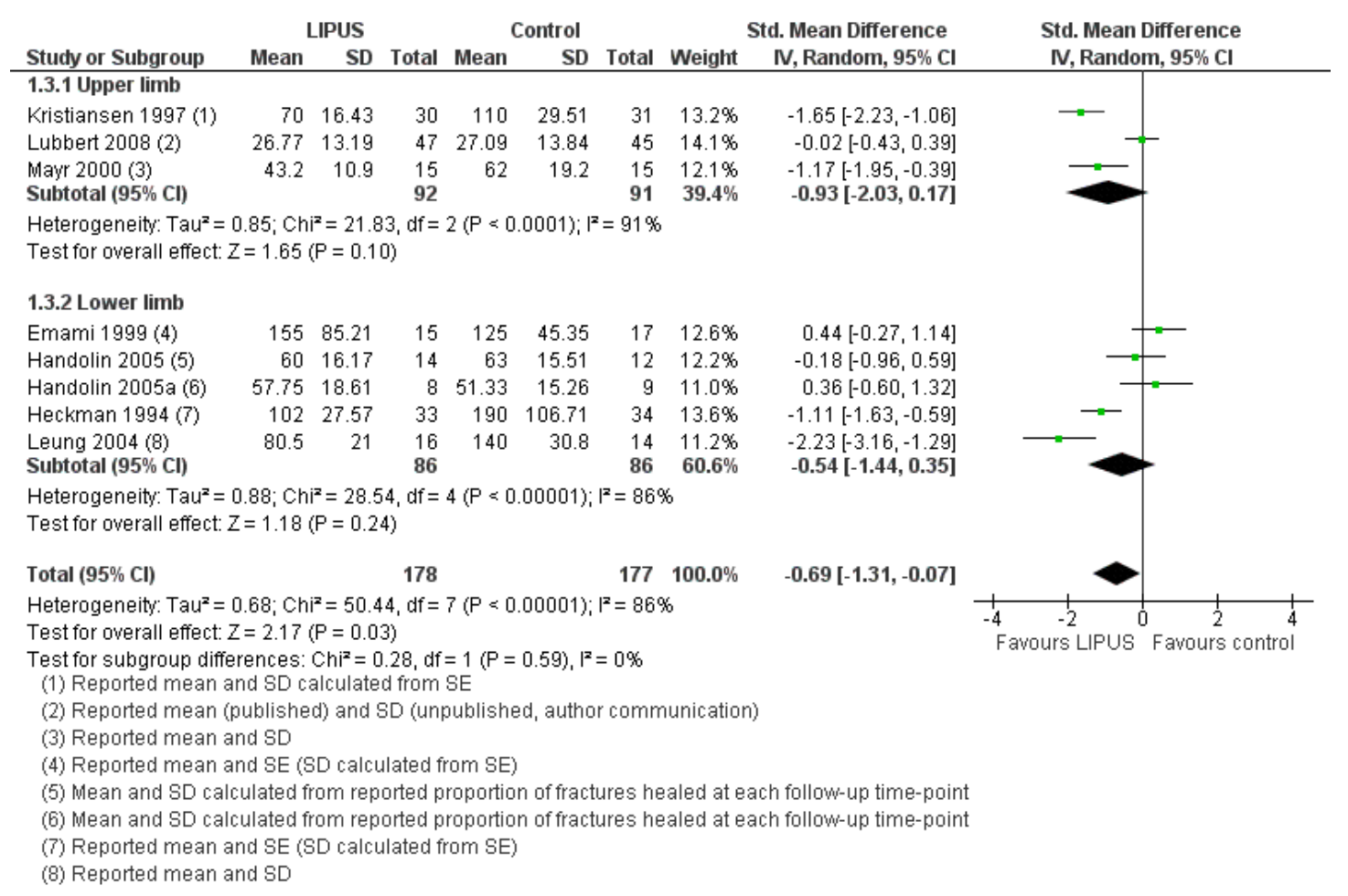




\section{Figure 3. Forest plot of comparison: I LIPUS versus control, outcome: I.4 Time to fracture radiographic}

union (days): worst case analysis.

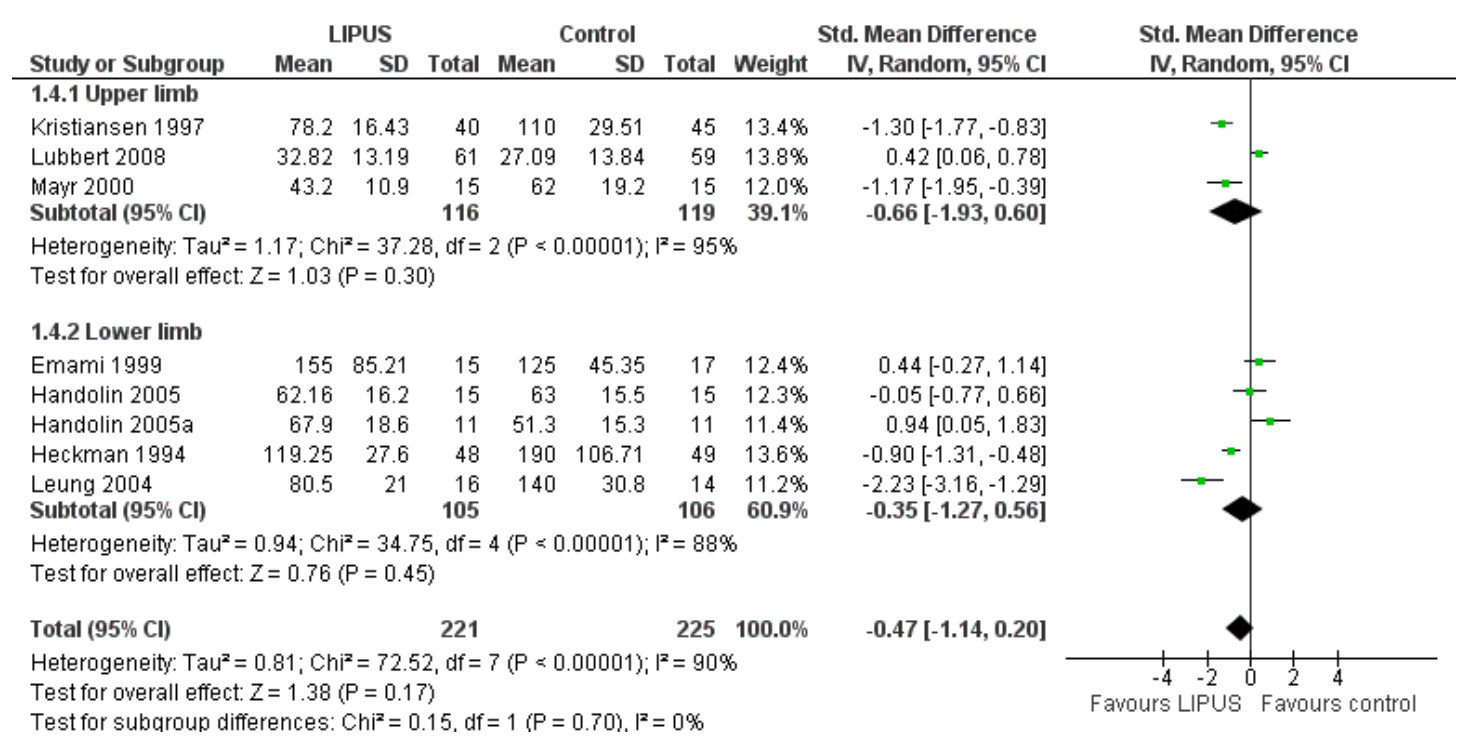

As reported above, there was very substantial statistical heterogeneity both in the pooled estimate of effect from all the studies and in the subgroup analyses ( $\mathrm{I}^{2}=90 \%$ for worst case analysis). We considered that this may be explained by the clinical variation in the treatment (operative versus conservative) of the participants between studies. We thus subgrouped the worst case analysis data by operative and conservative management (Figure 4; Analysis 1.5). The effect estimates from studies of participants with operatively treated fractures were substantially heterogenous and the precision of the estimate poor. The majority of the data from participants whose fractures were managed conservatively was consistent, excepting those from one study (Lubbert 2008). Importantly, Lubbert 2008 defined union quite differently from the other studies based upon participants' self-reports and this may be a reason for the observed heterogeneity in the estimate of effect. Excluding these data from Lubbert 2008 suggested a significant treatment effect due to ultrasound in this subgroup (SMD -1.09, $95 \%$ CI -1.38 to -0.80 ). However, the test for subgroup differences did not indicate that the findings of the two subgroups were statistically significantly different from each other $\left(\mathrm{Chi}^{2}=1.92\right.$, $\left.\mathrm{df}=1(\mathrm{P}=0.17), \mathrm{I}^{2}=47.8 \%\right)$. 
Figure 4. Forest plot of comparison: I LIPUS versus control, outcome: I.5 Time to fracture union (days) subgrouped by operation: worst case analysis.

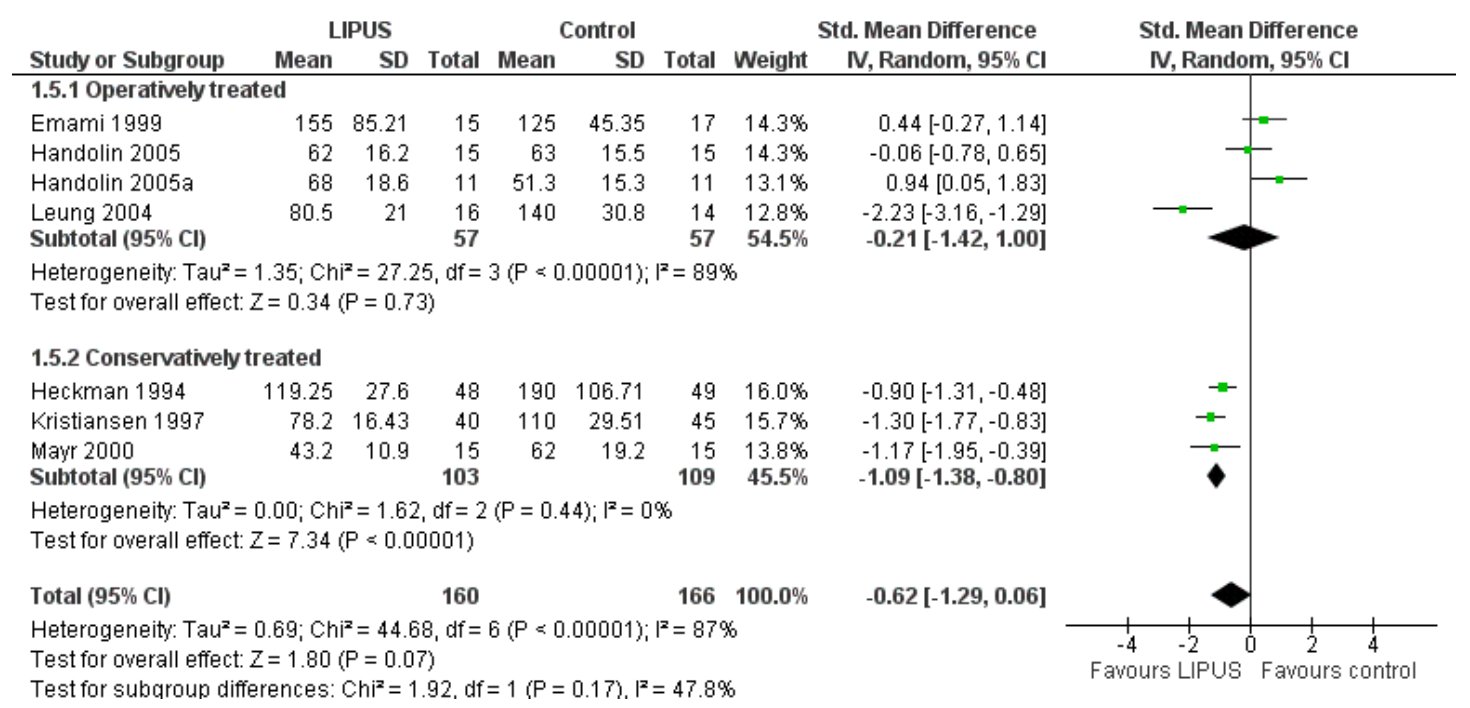

The trial reports of the included studies failed to present adequate data to conduct the two described a priori subgroup analyses in this review. However, Cook 1997 reported a retrospective subgroup analysis split by smoking status of the data from Heckman 1994 and Kristiansen 1997 (see Analysis 1.6). These results show that the effects of LIPUS were similar in both smokers and non-smokers (test for subgroup differences: $\mathrm{Chi}^{2}=0.05, \mathrm{df}=1(\mathrm{P}=0.83), \mathrm{I}^{2}=$ $0 \%)$.

Secondary outcomes

\section{Delayed union and non-union}

Figure 5 (Analysis 1.7) shows the available data for delayed or non-union. The different follow-up times and definition of this outcome are shown in the footnotes. The available data for all three upper limb fracture trials indicated that all fractures had eventually healed. Overall, the pooled data from five lower limb studies showed no significant difference between the treatment and control groups in this outcome (10/168 versus $13 / 165$; RR 0.75 ; $95 \%$ CI 0.24 to 2.28 ). 
Figure 5. Forest plot of comparison: I LIPUS versus control, outcome: I.7 Delayed or non-union (as reported analysis).

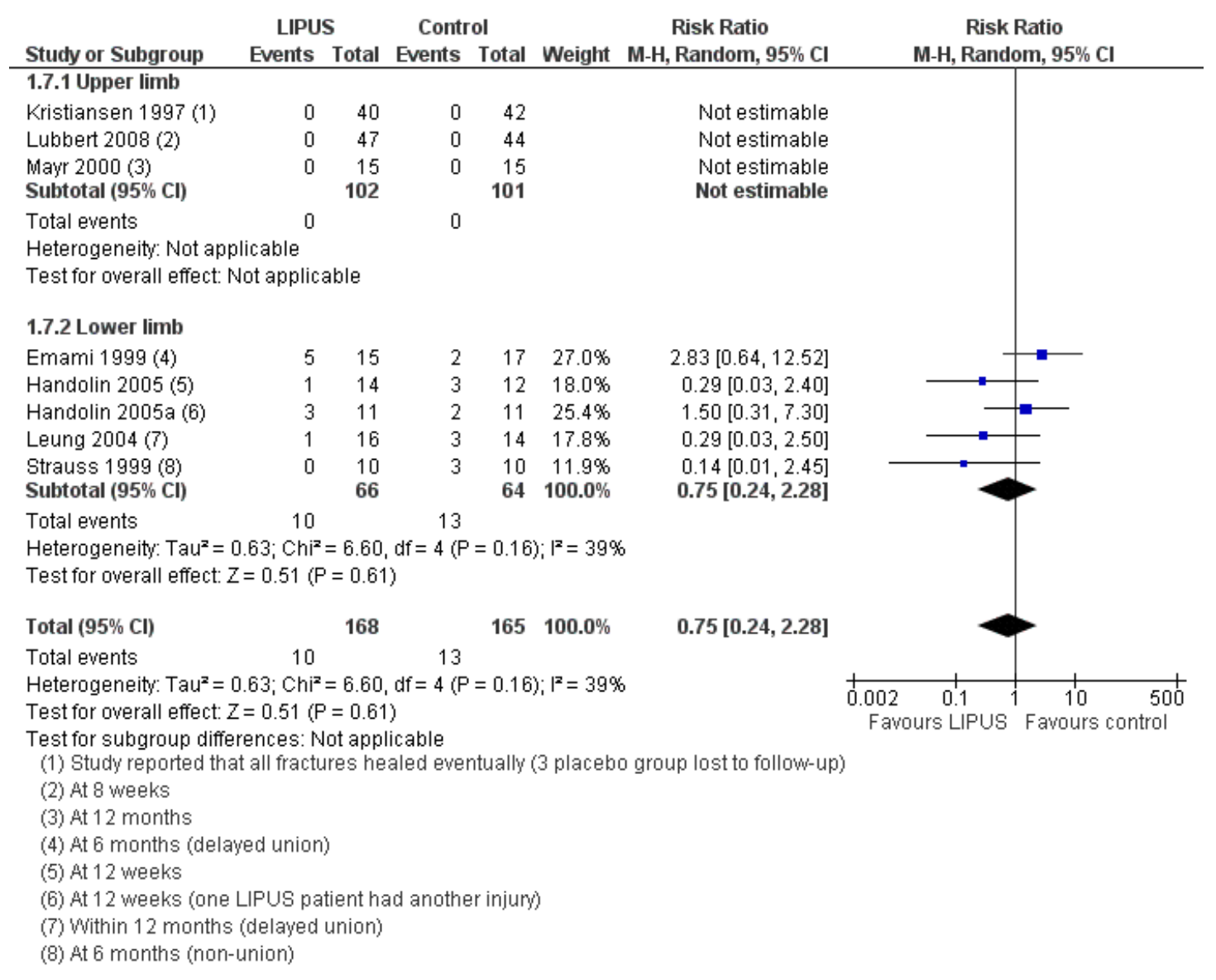

\begin{abstract}
Adverse events
Seven studies reported on adverse events. Emami 1999 reported no difference in the numbers of participants developing compartment syndrome ( 1 versus 2 ) or deep infection (0 versus 2$)$, or requiring the removal of locking screws (revision dynamisation: 2 versus 1 ). Several venous thromboembolic events were reported. Handolin 2005 found four deep vein thromboses, three of which were in the placebo group, Handolin 2005a reported one deep vein thrombosis in the placebo group and one participant suffered a pulmonary embolus in Heckman 1994. Three studies (Heckman 1994; Leung 2004; Lubbert 2008) reported a low incidence of self-resolving conditions (skin irritation, erythema and swelling), which did not lead to any trial protocol violations, and occurred in both treatment and placebo groups. Kristiansen 1997 reported that there had been no adverse reactions or complications attributable to the device reported during their study.
\end{abstract}

\section{Pain}

Lubbert 2008 reported visual analogue scores for pain (Analysis 1.8). An estimate from both the 'as reported' analysis and 'worst case' analysis showed no significant treatment effect (worst case analysis: MD $-0.02,95 \%$ CI -0.54 to 0.50 ) (Analysis 1.8 ).

\section{Cost}

None of the studies reported a health economics analysis.

\section{Adherence}

Several studies reported the recordings from both internal timers, contained within the devices, and participant treatment diaries. Emami 1999 reported good adherence to the trial protocol, with no significant difference between the treatment and placebo 
groups' usage or diary records, both of which closely matched the protocol requirements (ultrasound: mean $23.4 \mathrm{hrs}$, SD 0.8; placebo: $22.3 \mathrm{hrs}$ SD 1.0; participant diary: mean 24.6 hours). Kristiansen 1997 reported similar findings (ultrasound: mean 62 hours; placebo 64 hours) which compared favourably with the trial protocol requirement. Other studies (Handolin 2005; Heckman 1994) reported adherence less formally but did highlight good participant compliance. For instance, Handolin 2005 reported comparable duration of use of the ultrasound device (mean: 40.7 days versus 39.9 days). Participants of Rue 2004 were administered treatments by trial personnel so that adherence was easily determined. Both LIPUS and control groups missed a similar proportion of treatments, which was less than approximately $20 \%$ of all treatments in each group.

\section{Extracorporeal shock wave therapy (ECSW) versus control}

ECSW was tested only in Wang 2007, which compared ECSW with no ECSW in 56 patients with 59 fractures of the tibia or femur. Results in this trial were reported for fractures instead of participants; however, it was not possible to correct for the unit of analysis discrepancy.

\section{Primary outcomes}

Wang 2007 did not report on functional outcome or time to union.

\section{Secondary outcomes}

\section{Delayed union and non-union}

Wang 2007 found there was no significant effect of ECSW on non-union (all cases involved fractures of the femur) at 12 months (see Analysis 2.1: RR 0.56; 95\% CI 0.15 to 2.01). A sensitivity analysis where the fractures of the two excluded participants were assumed not to have united at 12 months gave similar results (RR $0.63,95 \%$ CI 0.21 to 1.93 ).

\begin{abstract}
Adverse events
Wang 2007 reported one case of deep infection and osteomyelitis in each group (both patients were excluded from the final analyses) and five cases of superficial infection (2/27 versus $3 / 30)$, all of which resolved with antibiotics and wound care. There were no other complications, including those directly related to shockwave treatment.
\end{abstract}

\section{Pain}

Wang 2007 found a clinically small but statistically significant difference in visual analogue scores for pain in favour of ECSW, from both the 'as reported' analysis (MD - $0.87,95 \% \mathrm{CI}-1.31$ to -0.43 ) and the 'worst case' analysis (MD - $0.80,95 \%$ CI -1.23 to 0.37 ) (Analysis 2.2). Similarly, pain scores were significantly lower in the ECSW group at six (1.19 versus 2.47) and 12 months (0.15 versus 0.77 ).

\section{Others}

Wang 2007 reported neither measures of cost nor adherence.

\section{I S C USSION}

\section{Summary of main results}

The review presented evidence from 11 trials comparing low intensity pulsed ultrasound (LIPUS) versus control, and one trial comparing extracorporeal shock wave therapy (ECSW) versus control. We found no trials evaluating high intensity focused ultrasound. The included trials form a clinically heterogeneous group of studies, which included participants with a range of acute fractures, treated in a variety of ways. The fractures were complete in 10 trials and stress fractures in two trials.

\section{Low intensity pulsed ultrasound versus control}

\section{Primary outcomes}

Neither of the two studies of complete fractures reporting functional outcomes found a difference between LIPUS compared with placebo control. Pooled results from two studies found that LIPUS had no significant effect on the time to return to training for soldiers or midshipmen with tibial stress fractures.

Data were pooled from eight small studies that reported the time to union of a complete fracture as a primary outcome following LIPUS. While the 'as reported' analysis indicated a significant benefit of LIPUS on time to union, a purposefully conservative 'worst case' analysis showed there was no statistically significant reduction in healing time of fresh fractures treated with LIPUS. However, a potential for greater benefit than harm from LIPUS should not be ruled out and the highly significant heterogeneity in the results indicates this potential may apply for some categories of patients. The two prespecified subgroup analyses by upper and lower limb fractures and smoking status did not show any differences between the subgroups. An additional subgroup analysis, comparing conservatively with surgically treated fractures, raised the possibility that LIPUS may be more effective in reducing healing time in conservatively managed fractures. However, while the 
results from the subset of the three trials of conservatively treated fractures (that measured time to union radiographically) were homogeneous, the test for differences between the conservative and surgical treatment subgroups was not statistically significantly different.

\section{Secondary outcomes}

Several studies reported the proportion of participants going on to develop delayed union or non-union. However, the reporting, measurement and definition of these outcomes varied. We found no significant difference between the treatment and control groups in the pooled result.

Importantly, the compliance with LIPUS treatment was found to be good and the adverse effects directly associated with its use (or associated devices) were found to be few and minor. Thus this review provides reasonably good evidence that such a treatment would be acceptable to patients in general clinical practice.

Only one study reported pain scores using visual analogue scales, finding no difference between groups at eight weeks. There were no data on costs.

\section{Extracorporeal shock wave therapy (ECSW) versus control}

The small quasi-randomised trial evaluating ECSW, for tibia and femur fractures, did not report on functional outcomes nor time to union. It found no significant improvement in the proportion of people achieving union following ECSW at 12 months. There were, however, clinically small but statistically significant differences in the visual analogue scores for pain in favour of ECSW at three, six and 12 month follow-ups. The only reported complication was infection, with no significant differences between the two groups.

\section{Overall completeness and applicability of evidence}

\section{Completeness of the evidence}

This review includes data from 11 studies, conducted in seven countries, testing the use of ultrasound for acute fractures in a total of 566 adults. Nine studies concerned the treatment of complete fractures; Rue 2004 and Yadav 2008 reported the outcomes in participants with stress fractures. The evidence for ECSW therapy was restricted to that from one small study involving 56 adults (Wang 2007). We found no trials evaluating high intensity focused ultrasound. While the total population represents a minute proportion of the acute fractures occurring annually, the fractures included in the studies are some of those characterised by higher incidences of delayed and non-union.
Few of the studies reported functional patient reported outcome measures or return to limb function or work. There was a considerable proportion of data missing for time to union, the other primary outcome of this review. This in part may reflect the difficulties in measuring this outcome. There was little evidence regarding pain or adverse events. Participant adherence to the treatment protocols was reported to an extent.

\section{Application of the evidence to current practice}

The included studies reported the use of ultrasound in a wide variety of settings and participants. Most settings were typical hospital settings, such as in Europe and the United States. The participants included those with fractures of the upper or lower limbs, which were treated either surgically or conservatively. Although these populations were highly heterogeneous, they are still representative of the type of fracture populations, generally at higher risk of delayed healing and non-union, for which treatment adjuncts might be considered.

Clinical practice varies worldwide but LIPUS remains a specialist treatment usually only considered for, or administered to, patients with fractures at risk of delayed union or non-union. The evidence from this review would not seem to encourage the wider clinical application of LIPUS at this time. It does, however, support the widely held view that LIPUS is safe and acceptable to patients.

\section{Quality of the evidence}

\section{Sources of systematic error}

The quality of reporting of the included studies was moderate only, with insufficient details to judge risk of bias. All bar two studies were randomised, but in only three could we assign a low risk of selection bias relating to allocation concealment. Most trials were blinded through the use of sham devices but even so, the lack of identical devices in Leung 2004 put this quasi-randomised trial at high risk of performance and detection bias.

All of the studies were small and therefore the likelihood of an imbalance in the baseline characteristics is high. This could be unknown or not reported; for example, only three studies adequately report the baseline smoking behaviour of the participants (Emami 1999; Heckman 1994; Kristiansen 1997).

There was also a considerable proportion of data missing. Several of the lead authors of the studies were contacted during this review and each reported that they had struggled to maintain participant compliance with the demanding follow-up schedule required to determine time to union. We have chosen to handle the missing data in such a way to make a conservative estimate of any treatment effect. 


\section{Other sources of error}

The individual studies reported here are small and often underpowered. This is reflected in the imprecision and heterogeneity of the study estimates of treatment effects. The largest pool of data concerned the time to fracture union. Reported data from 355 participants were available to determine the effect of LIPUS on the time to fracture union. This might be sufficient to detect a large, clinically relevant effect, although the problem of missing data cannot be ignored. The number of participants included in the other reported pooled analyses is lower, and therefore the conclusions about these important outcomes are necessarily even more tentative.

The primary outcome of fracture healing is variably defined in the literature. As anticipated, we found that studies defined healing clinically and radiographically. This reflects the difficulty that is inherent in the assessment of union. The choice of measurement tool and the timing of assessments of union varied between studies. Radiographic union commonly follows behind clinical union and can be difficult to determine from plain radiographs. None of the included studies used a panel of independent radiologists to assess radiographic union.

\section{Potential biases in the review process}

None of the authors of this review have been involved in any of the included trials or have any commercial or other conflict of interest.

We predominantly searched the published literature. Despite efforts to contact experts we have not found any unpublished data. Given that trial registration was limited during the period over which most of these studies were conducted, it is possible that commercially sponsored negative trials were not published. We have also not searched conference abstracts. It is therefore possible that there are other trials and trial data that have not been included in this review. It is not possible to estimate the potential effects of these on the review findings. However, some reassurance can be gained from the finding that a recent systematic review by Busse 2009 found no additional studies that fulfilled our inclusion criteria.

There was significant heterogeneity in the meta-analyses. We conducted a post hoc sensitivity analysis to try to explore the sources of heterogeneity between the studies. We made these decisions through consensus with a view to dealing with the available data in a pragmatic manner. However, the decisions regarding the pooling of data were necessarily subjective and may be a cause of bias. The rational for our conjecture of a difference between conservatively and operatively (where rigid fixation methods are used) treated fractures is that in the former, ultrasound might cause micromotion at the fracture site leading to accelerated union, whereas in the latter such micromotion might be impossible and any benefit of ultrasound lost. This hypothesis was not confirmed by the data available so far to this review.
We have attempted to contact the authors of included studies to retrieve missing data with mixed success. There may be a systematic difference between those authors who we have been able to contact and those that we have not. Some existing data have therefore been excluded or not retrieved by this review.

\section{Agreements and disagreements with other studies or reviews}

The findings of this review are in keeping with a recent systematic review on the effects of LIPUS for fractures (Busse 2009). Busse 2009 also included trials testing the effects of LIPUS on non-union (one trial) and 'distraction osteogenesis' (three trials). In keeping with our review, Busse 2009 observed the conflicting results from the included trials and concluded that the evidence, while promising, was not enough to establish the role of LIPUS in the management of fractures.

\section{A U THORS' CONCLUSIONS}

\section{Implications for practice}

This review highlights the limitations of the available evidence on therapeutic ultrasound for acute fractures in adults. Currently, the best assessment of the clinical effectiveness of LIPUS for complete or stress fractures in adults does not support the routine use of this intervention in clinical practice.

\section{Implications for research}

The identification of three unpublished trials, the largest of which is ongoing, points to importance of both the timely publication of the results of these trials and the regular updating of this review. Two of these trials involve surgically treated tibial fractures and one involves conservatively treated tibial fractures. While conclusive evidence on time to union may result from the largest trial (TRUST (Full)) should it recruit 500 participants, it is regrettable that the opportunity to collect patient-reported outcome measures appears to have been overlooked. Any future research, which should involve secure randomisation and placebo controls, on the use of ultrasound for acute fractures should focus on patient-reported outcome measures to determine if the possible benefit of ultrasound in terms of fracture healing translates into a tangible benefit to patients. Trials should conform to reporting standards as set out in the CONSORT statement, including reporting the results of all trial participants (Boutron 2008). 


\section{ACK NOWLEDGEMENTS}

We would like to thank the trial authors Jason Busse, Joan McCabe, James Heckman and Pieter Lubbert, each of whom responded positively to our requests for further information about their studies. We would also like to thank Anette Bluemle and Juliane Ried from the German Cochrane Centre for their help in translation of one of the studies.

The authors would like to thank Prof William Gillespie, Dr Helen Handoll, Dr James D Heckman, Prof Peter Herbison and Dr Vicki Livingstone for valuable comments on the protocol and review. We also acknowledge the help of Mrs Lesley Gillespie in developing the search strategies, and the editorial base staff for their help in the processes of writing the protocol and review.

\section{RE FER E NCE S}

\section{References to studies included in this review}

\section{Emami 1999 \{published data only\}}

Emami A, Petren-Mallmin M, Larsson S. No effect of lowintensity ultrasound on healing time of intramedullary fixed tibial fractures. Journal of Orthopaedic Trauma 1999;13(4): $252-7$

\section{Handolin 2005 \{published data only (unpublished sought but not} used)\}

Handolin L, Kiljunen V, Arnala I, Kiuru MJ, Pajarinen J, Partio EK, et al. No long-term effects of ultrasound therapy on bioabsorbable screw-fixed lateral malleolar fracture. Scandinavian Journal of Surgery 2005;94(3):239-42.

* Handolin L, Kiljunen V, Arnala I, Pajarinen J, Partio EK, Rokkanen P. The effect of low intensity ultrasound and bioabsorbable self-reinforced poly-L-lactide screw fixation on bone in lateral malleolar fractures. Archives of Orthopaedic and Trauma Surgery 2005;125(5):317-21.

Handolin 2005a \{published data only (unpublished sought but not used)\}

Handolin L, Kiljunen V, Arnala I, Kiuru MJ, Pajarinen J, Partio EK, et al. Effect of ultrasound therapy on bone healing of lateral malleolar fractures of the ankle joint fixed with bioabsorbable screws. Journal of Orthopaedic Science 2005;10(4):391-5.

\section{Heckman 1994 \{published and unpublished data\}}

Cook S, Ryaby JP, Heckmann JD, Kristiansen TK. Lowintensity pulsed ultrasound accelerates tibia and distal radius fracture healing in smokers. Hefte zur der Unfallchirurg 1996;262:336.

Cook SD, Ryaby JP, McCabe J, Frey JJ, Heckman JD, Kristiansen TK. Acceleration of tibia and distal radius fracture healing in patients who smoke. Clinical Orthopaedics \& Related Research 1997;(337):198-207. Cook SD, Ryaby JP, McCabe J, Frey JJ, Heckman JD, Kristiansen TK. Low intensity pulsed ultrasound accelerates tibia and distal radius fracture healing in smokers [abstract]. Orthopaedic Transactions 1996;20(1):56.

Heckman JD. Personal communication September 22010 * Heckman JD, Ryaby JP, McCabe J, Frey JJ, Kilcoyne RF. Acceleration of tibial fracture-healing by non-invasive, low-intensity pulsed ultrasound. Journal of Bone and Joint Surgery - American Volume 1994;76(1):26-34.

Kristiansen 1997 \{published and unpublished data\} Cook S, Ryaby JP, Heckmann HD, Kristiansen TK. Lowintensity pulsed ultrasound accelerates tibia and distal radius fracture healing in smokers. Hefte zur der Unfallchirurg 1996;262:336.

Cook SD, Ryaby JP, McCabe J, Frey JJ, Heckman JD, Kristiansen TK. Acceleration of tibia and distal radius fracture healing in patients who smoke. Clinical Orthopaedics \& Related Research 1997;(337):198-207. Cook SD, Ryaby JP, McCabe J, Frey JJ, Heckman JD, Kristiansen TK. Low intensity pulsed ultrasound accelerates tibia and distal radius fracture healing in smokers [abstract]. Orthopaedic Transactions 1996;20(1):56.

Kristiansen TK, Ryaby JP, McCabe J, Frey J. Controlling loss of reduction in distal radius fractures in an randomized, double-blind study using low-intensity ultrasound. Hefte zur der Unfallchirurg. 1996; Vol. 262:369.

Kristiansen TK, Ryaby JP, McCabe J, Frey J. Controlling loss of reduction in distal radius fractures with low intensity pulsed ultrasound [abstract]. Orthopaedic Transactions 1997;21(1):141.

* Kristiansen TK, Ryaby JP, McCabe J, Frey JJ, Roe LR. Accelerated healing of distal radial fractures with the use of specific, low-intensity ultrasound: A multicenter, prospective, randomized, double- blind, placebo-controlled study. Journal of Bone and Joint Surgery - American Volume 1997;79(7):961-73.

McCabe J. Personal communication September 222010.

Leung 2004 \{published data only\}

Leung KS, Lee WS, Tsui HF, Liu PPL, Cheung WH. 
Complex tibial fracture outcomes following treatment with low-intensity pulsed ultrasound. Ultrasound in Medicine and Biology 2004;30(3):389-95.

\section{Lubbert 2008 \{published and unpublished data\}}

Lubbert PH. Personal communication November 72010.

* Lubbert PHW, van der Rijt RHH, Hoorntje LE, van der Werken C. Low-intensity pulsed ultrasound (LIPUS) in fresh clavicle fractures: A multi-centre double blind randomised controlled trial. Injury 2008;39(12):1444-52.

Mayr 2000 \{published data only\}

Mayr E. Accelerated healing of scaphoid fracture - a randomized study [abstract]. Journal of Bone and Joint Surgery - British Volume 1999;81 Suppl 2:206.

Mayr E, Rudzki M, Borchardt B, Ruter A. Accelerated healing of scaphoid fractures - A randomized study [abstract]. Journal of Orthopaedic Trauma 1999;13(4):310. * Mayr E, Rudzki M-M, Rudzki M, Borchardt B, Hausser H, Ruter A. Does Pulsed Low-Intensity Ultrasound Accelerate Healing of Scaphoid Fractures? [Beschleunigt niedrig intensive, gepulster Ultraschall die Heilung von Skaphoidfrakturen?]. Handchirurgie Mikrochirurgie Plastische Chirurgie 2000;32(2):115-22.

Rue 2004 \{published data only\}

Rue JP, Armstrong DW 3rd, Frassica FJ, Deafenbaugh $\mathrm{M}$, Wilckens JH. The effect of pulsed ultrasound in the treatment of tibial stress fractures. Orthopedics 2004;27(11): 1192-5.

Strauss 1999 \{published data only (unpublished sought but not used)\} Strauss E, Ryaby JP, McCabe J. Treatment of Jones' fractures of the foot with adjunctive use of low-pulsed ultrasound stimulation. Journal of Orthopaedic Trauma 1999;13(4): 310.

Wang 2007 \{published data only\}

Liu HC, Fu TH. Effects of shockwave on acute highenergy fractures of the femur and tibia [abstract]. American Academy of Orthopaedic Surgeons Annual Meeting. Febuary 2007.

* Wang CJ, Liu HC, Fu TH. The effects of extracorporeal shockwave on acute high-energy long bone fractures of the lower extremity. Archives of Orthopaedic and Trauma Surgery 2007;127(2):137-42.

Yadav 2008 \{published data only\}

Yadav YK, Salgotra KR, Banerjee A. Role of ultrasound therapy in the healing of tibial stress fractures. Medical Journal Armed Forces India 2008;64(3):234-6.

\section{References to studies excluded from this review}

\section{Basso 1998 \{published data only\}}

Basso O, Pike JM. The effect of low frequency, long-wave ultrasound therapy on joint mobility and rehabilitation after wrist fracture. Journal of Hand Surgery - British Volume 1998;23(1):136-9.

Busse 2005 \{published data only\}

Busse JW, Bhandari M, Sprague S, Johnson-Masotti AP, Gafni A. An economic analysis of management strategies for closed and open grade I tibial shaft fractures. Acta Orthopaedica 2005;76(5):705-12.

Heckman 1997 \{published data only\}

Heckman JD, Sarasohn-Kahn J. The economics of treating tibia fractures: The cost of delayed unions. Bulletin of The Hospital for Joint Dieases 1997;56(1):63-72.

\section{References to studies awaiting assessment}

\section{ISRCTN90844675 \{unpublished data only\}}

Seifert J. Pulsed ultrasound to speed-up healing after intramedullary nailing of tibia fractures (PUSHIT). http://controlled-trials.com/ISRCTN90844675/ ISRCTN90844675 (accessed 9 December 2011).

\section{TRUST (Pilot) \{unpublished data only\}}

* Bhandari M, Busse J, Guyatt G. Trial to re-evaluate ultrasound in the treatment of tibial fractures (TRUST). http://www.controlled-trials.com/ISRCTN98682811 (accessed 14 June 2011).

Busse J. personal communication 20 December 2011.

\section{References to ongoing studies}

TRUST (Full) \{unpublished data only\}

Bhandari M. Trial to re-evaluate ultrasound in the treatment of tibial fractures (TRUST). http://www.clinicaltrials.gov/ ct2/show/NCT00667849 (accessed 7 December 2011).

\section{Additional references}

\section{Aaron 2004}

Aaron RK, Ciombor DM, Simon BJ. Treatment of nonunions with electric and electromagnetic fields. Clinical Orthopaedics \& Related Research 2004;(419):21-9. [PUBMED: 15021127]

\section{Boutron 2008}

Boutron I, Moher D, Altman DG, Schulz KF, Ravaud P, CONSORT Group. Extending the CONSORT statement to randomized trials of nonpharmacologic treatment: explanation and elaboration. Annals of Internal Medicine 2008;148(4):295-309.

Busse 2009

Busse JW, Kaur J, Mollon B, Bhandari M, Tornetta P 3rd, Schunemann HJ, et al. Low intensity pulsed ultrasonography for fractures: systematic review of randomised controlled trials. BMJ 2009;338:b351.

Busse 2011

Busse J. personal communication 20 December 2011.

Cook 1997

Cook SD, Ryaby JP, McCabe J, Frey JJ, Heckman JD, Kristiansen TK. Acceleration of tibia and distal radius fracture healing in patients who smoke. Clinical Orthopaedics \& Related Research 1997;(337):198-207.

\section{Einhorn 1995}

Einhorn TA. Enhancement of fracture healing. Journal of Bone \& Joint Surgery - American Volume 1995;77(6): 940-56. [MEDLINE: 7782368] 


\section{Griffin 2008}

Griffin XL, Costello I, Costa ML. The role of low intensity pulsed ultrasound therapy in the management of acute fractures: a systematic review. Journal of Trauma-Injury Infection \& Critical Care 2008;65(6):1446-52. [PUBMED: 19077640]

\section{Hadjiargyrou 1998}

Hadjiargyrou M, McLeod K, Ryaby JP, Rubin C. Enhancement of fracture healing by low intensity ultrasound. Clinical Orthopaedics \& Related Research 1998; (355 Suppl):S216-29. [PUBMED: 9917641]

\section{Handolin 2005b}

Handolin L, Kiljunen V, Arnala I, Kiuru MJ, Pajarinen J, Partio EK, et al. No long-term effects of ultrasound therapy on bioabsorbable screw-fixed lateral malleolar fracture. Scandinavian Journal of Surgery 2005;94(3):239-42.

\section{Higgins 2003}

Higgins JP, Thompson SG, Deeks JJ, Altman DG. Measuring inconsistency in meta-analyses. BMJ 2003;327 (7414):557-60. [MEDLINE: 12958120]

\section{Higgins 2008}

Higgins JPT, Altman DG. Chapter 8: Assessing risk of bias in included studies. In: Higgins JPT, Green S editor(s). Cochrane Handbook for Systematic Reviews of Interventions. Chichester: John Wiley \& Sons, 2008.

\section{Lefebvre 2009}

Lefebvre C, Manheimer E, Glanville J. Chapter 6: Searching for studies. In: Higgins JPT, Green S (editors). Cochrane Handbook for Systematic Reviews of Interventions Version 5.0.2 [updated September 2009]. The Cochrane Collaboration, 2009. Available from www.cochranehandbook.org.

\section{Reher 1997}

Reher P, Elbeshir el-NI, Harvey W, Meghji S, Harris M. The stimulation of bone formation in vitro by therapeutic ultrasound. Ultrasound in Medicine \& Biology 1997;23(8): 1251-8. [PUBMED: 9372573]

\section{Victoria 2009}

Victoria G, Petrisor B, Drew B, Dick D. Bone stimulation for fracture healing: What's all the fuss?. Indian Journal of Orthopaedics 2009;43(2):117-20.

\section{Wang 1994}

Wang SJ, Lewallen DG, Bolander ME, Chao EY, Ilstrup DM, Greenleaf JF. Low intensity ultrasound treatment increases strength in a rat femoral fracture model. Journal of Orthopaedic Research 1994;12(1):40-7. [PUBMED: 8113941]

* Indicates the major publication for the study 
CHARACTERISTICS OF STUDIES

Characteristics of included studies [ordered by study ID]

Emami 1999

\begin{tabular}{ll}
\hline Methods & Randomised, placebo-controlled study. \\
\hline Participants & Setting: Uppsala University Hospital, Sweden. \\
& Size: 30 participants in total, with 15 in each arm. \\
& Baseline characteristics: mean (range) age 39 years (19 to 73), 21 males and 9 females \\
& Inclusion criteria: patients aged over 16 years with a closed or Gustillo and Anderson \\
& grade I open fracture of the tibial diaphysis treated with closed reduction and fixation \\
with a reamed, intra-medullary, locked nail & Exclusion criteria: history of alcohol or drug dependency; current steroid, anticoagulant, \\
& NSAID or bisphosphonate use; past medical history of neuropathy, arthritis, malignant \\
& disease; radiographs that showed severe comminution or open physes \\
\hline
\end{tabular}

Interventions

Participants underwent closed reduction and reamed, intra-medullary nailing of the fracture. Surgery was performed by one of six experienced trauma surgeons. The fracture site was marked with a permanent skin marker.

Test: ultrasound treatment was started within three days of fixation and was continued for 75 days. The treatment consisted of one 20 minute period daily with a maximum exposure of 25 hours. The transducer head was coupled to the skin with a standard gel. The ultrasound signal was composed of a $200 \mu$ s burst of $1.5 \mathrm{MHz}$ sine waves, with a repetition rate of $1 \mathrm{kHz}$ and a spatial average intensity of $30 \mathrm{~mW} / \mathrm{cm}^{2}$

Control: sham ultrasound treatment was started within three days of fixation and was continued for 75 days. The treatment consisted of one 20 minute period daily with a maximum exposure of 25 hours. The sham device was a deactivated, identical model to that provided to the test group

$\begin{array}{ll}\text { Futcomes } & \text { Follow-up schedule: every third week until union. Additional follow-up at } 26 \text { and } 52 \\ \text { weeks irrespective of union status } \\ \text { Primary: time to radiographic union. } \\ \text { Secondary: time to first radiographic evidence of callus, proportion of fractures united } \\ \text { at six months, adverse events }\end{array}$

Outcomes were assessed by a single blinded radiologist and an orthopaedic surgeon independently, but were not pooled

\section{Risk of bias}

\begin{tabular}{lll}
\hline Bias & Authors' judgement & Support for judgement \\
\hline $\begin{array}{l}\text { Random sequence generation (selection } \\
\text { bias) }\end{array}$ & Unclear risk & $\begin{array}{l}\text { Quote: "The study was ... randomized” } \\
\text { Comment: No specific report of how the se- } \\
\text { quence was generated }\end{array}$ \\
\hline Allocation concealment (selection bias) & Unclear risk & The allocation method was not reported.
\end{tabular}




\section{Emami 1999 (Continued)}

Blinding (performance bias and detection Low risk bias)

Patient reported measures
No patient reported measures included in the study.
Blinding (performance bias and detection Low risk

bias)

Objective measures
Quotes: "The codes were not broken for any device until the radiographic reviews for all patients had been completed."

"...devices were identical in every way..."

Comment: All measures were adequately blinded.

Incomplete outcome data (attrition bias) Low risk Patient reported measures

No patient reported measures included in the study.

Quote: "In one patient, it became obvious during the course of the study that he did not fulfil the inclusion/exclusion criteria."

Comment: No data were reported for this single participant and he was excluded from the analysis

\begin{tabular}{|c|c|c|}
\hline Selective reporting (reporting bias) & Unclear risk & No protocol available. \\
\hline Other bias & High risk & $\begin{array}{l}\text { Quote: "All radiographs were assessed sepa- } \\
\text { rately in independent blind reviews by a mus- } \\
\text { culoskeletal radiologist...and an orthopaedic } \\
\text { trauma surgeon." } \\
\text { Comment: These outcomes are not pooled } \\
\text { but rather presented separately. The data used } \\
\text { in this review is that derived from the single } \\
\text { independent radiologist }\end{array}$ \\
\hline
\end{tabular}

Selection bias (imbalance in baseline char- Low risk acteristics)

Baseline data for age, sex and smoking status are reported and show a balanced distribution of these confounders between groups

Handolin 2005

\begin{tabular}{|c|c|}
\hline Methods & Randomised, placebo-controlled study. \\
\hline Participants & $\begin{array}{l}\text { Setting: Helsinki University Central Hospital, Finland. } \\
\text { Size: } 30 \text { patients in total, } 15 \text { in each arm. } \\
\text { Baseline characteristics: mean age } 41.4 \text { years ( } 5 \text { male/ } 10 \text { female) in intervention group } \\
\text { and } 39.4 \text { years ( } 8 \text { male/7 female) in the control group } \\
\text { Inclusion criteria: patients aged between } 18 \text { and } 65 \text { years with displaced Weber B fractures } \\
\text { of the lateral malleolus } \\
\text { Exclusion criteria: widening of the distal tibiofibular joint; open fracture; inability to co- } \\
\text { operate with the requirements of the trial }\end{array}$ \\
\hline
\end{tabular}


Handolin 2005 (Continued)

\begin{tabular}{|c|c|}
\hline Interventions & $\begin{array}{l}\text { Participants underwent open reduction and internal fixation with a } 4.5 \mathrm{~mm} \text { self-rein- } \\
\text { forced poly-L-lactic acid screw. Surgery was carried out by one of two surgeons. The } \\
\text { fracture was approached through a lateral incision. Post-operatively the ankle was im- } \\
\text { mobilised for six weeks with a removable Soft Cast brace. Partial weight bearing was } \\
\text { allowed at two weeks and full weight bearing at four weeks } \\
\text { Test: participants self-administered daily ultrasound treatment for } 20 \text { minutes from the } \\
\text { third to ninth post-operative weeks directly over the fracture marked an intra-operatively } \\
\text { placed marker. Appropriate contact between the probe and the skin was maintained with } \\
\text { standard ultrasound coupling gel. The ultrasound signal was composed of a } 200 \mu \text { burst } \\
\text { of } 1.5 \mathrm{MHz} \text { sine waves, with a repetition rate of } 1 \mathrm{kHz} \text { and a spatial average intensity of } \\
30 \mathrm{~mW} / \mathrm{cm}^{2} \\
\text { Control: participants in the control group were given a similar treatment regimen but } \\
\text { had an externally similar sham machine instead }\end{array}$ \\
\hline Outcomes & $\begin{array}{l}\text { Follow-up schedule was } 2,6,9 \text { and } 12 \text { week and, in a separate publication, } 18 \text { months } \\
\text { At } 18 \text { months, the clinical outcome was assessed using the Olerud-Molander scoring as } \\
\text { well as clinical examination; this was reported in a separate article for } 16 \text { (8 versus } 8 \text { ) } \\
\text { participants } \\
\text { Plain radiographic assessment at } 2,6,9 \text { and } 12 \text { weeks and at } 18 \text { months. Multi detector } \\
\text { computed tomography (MDCT) at } 18 \text { months and dual-energy X-ray absorptiometry } \\
\text { (DEXA) scan post operatively and at } 18 \text { months }\end{array}$ \\
\hline
\end{tabular}

Notes

Based on overlapping, but not matching, dates of recruitment we have assumed that a publication (Handolin 2005b) reporting 18 month results for 16 participants is a longterm follow-up of this trial. These reports share a common methodology and reporting framework. Efforts to contact the authors were unsuccessful

Risk of bias

\begin{tabular}{|c|c|c|}
\hline Bias & Authors' judgement & Support for judgement \\
\hline $\begin{array}{l}\text { Random sequence generation (selection } \\
\text { bias) }\end{array}$ & Unclear risk & $\begin{array}{l}\text { Quote: "...prospective, randomised ... study." } \\
\text { Comment: The method of sequence genera- } \\
\text { tion is not reported. }\end{array}$ \\
\hline Allocation concealment (selection bias) & Unclear risk & $\begin{array}{l}\text { The method of allocation concealment is not } \\
\text { reported }\end{array}$ \\
\hline
\end{tabular}

Blinding (performance bias and detection Low risk None reported.

bias)

Patient reported measures

Blinding (performance bias and detection Low risk bias)

Objective measures
Quote: "double blind; half of the devices were active ... half were sham."

Comment: Likely to be the same device but placebo devices were deactivated 
Handolin 2005 (Continued)

\begin{tabular}{|c|c|c|}
\hline $\begin{array}{l}\text { Incomplete outcome data (attrition bias) } \\
\text { Patient reported measures }\end{array}$ & Low risk & None reported \\
\hline $\begin{array}{l}\text { Incomplete outcome data (attrition bias) } \\
\text { Objective measures }\end{array}$ & High risk & $\begin{array}{l}\text { All outcome data reported up to } 12 \text { weeks, but } \\
\text { data from only } 16 \text { participants reported at } 18 \\
\text { months }\end{array}$ \\
\hline Selective reporting (reporting bias) & Unclear risk & No protocol available. \\
\hline Other bias & Unclear risk & $\begin{array}{l}\text { It is not reported how the radiographic out- } \\
\text { comes were assessed }\end{array}$ \\
\hline $\begin{array}{l}\text { Selection bias (imbalance in baseline char- } \\
\text { acteristics) }\end{array}$ & Unclear risk & $\begin{array}{l}\text { Age and sex similarly distributed, but smoking } \\
\text { status not reported }\end{array}$ \\
\hline
\end{tabular}

Handolin 2005a

\begin{tabular}{ll}
\hline Methods & Randomised, placebo-controlled study. \\
\hline Participants & Setting: Helsinki Unversity Central Hospital, Finland. \\
& $\begin{array}{l}\text { Size: } 22 \text { patients, } 11 \text { in each arm. } \\
\text { Baseline characteristics: mean (range) age } 37.5 \text { years (18 to } 54), 9 \text { males and } 2 \text { females } \\
\text { in intervention group. Mean (range) age } 45.5 \text { years (26 to 59), } 6 \text { males and } 5 \text { females in } \\
\text { the control group } \\
\text { Inclusion criteria: patients aged between } 18 \text { and } 65 \text { years with displaced Weber B fractures } \\
\text { of the lateral malleolus } \\
\text { Exclusion criteria: widening of the distal tibiofibular joint; open fracture; inability to co- } \\
\text { operate with the requirements of the trial }\end{array}$ \\
\hline
\end{tabular}

Interventions

Participants underwent open reduction and internal fixation with a $4.5 \mathrm{~mm}$ self-reinforced poly-L-lactic acid screw. Surgery was carried out by one of two surgeons. The fracture was approached through a lateral incision. Post-operatively the ankle was immobilised for six weeks with a removable Soft Cast brace. Partial weight bearing was allowed at two weeks and full weight bearing at four weeks

Test: participants self-administered daily ultrasound treatment for 20 minutes from the third to ninth post-operative weeks directly over the fracture marked an intra-operatively placed marker. Appropriate contact between the probe and the skin was maintained with standard ultrasound coupling gel. The ultrasound signal was composed of a $200 \mu$ s burst of $1.5 \mathrm{MHz}$ sine waves, with a repetition rate of $1 \mathrm{kHz}$ and a spatial average intensity of $30 \mathrm{~mW} / \mathrm{cm}^{2}$

Control: participants in the control group were given a similar treatment regime but had an externally similar sham machine instead

Outcomes

Fracture healing was assessed by anterior and lateral radiographs taken immediately and at 2, 6, 9 and 12 weeks postoperatively

In addition, fracture healing was assessed by multiplanar computed tomography and 2 and 9 weeks postoperatively 
Handolin 2005a (Continued)

Notes

Risk of bias

\begin{tabular}{|c|c|c|}
\hline Bias & Authors' judgement & Support for judgement \\
\hline $\begin{array}{l}\text { Random sequence generation (selection } \\
\text { bias) }\end{array}$ & Unclear risk & $\begin{array}{l}\text { Quote: “..prospective, randomized, double- } \\
\text { blind and placebo controlled study”. No com- } \\
\text { ment on sequence generation }\end{array}$ \\
\hline Allocation concealment (selection bias) & Low risk & $\begin{array}{l}\text { Quote: "The patients were randomly pro- } \\
\text { vided with either an active or sham ultrasound } \\
\text { device in a double-blind manner" }\end{array}$ \\
\hline $\begin{array}{l}\text { Blinding (performance bias and detection } \\
\text { bias) } \\
\text { Patient reported measures }\end{array}$ & Low risk & None reported. \\
\hline
\end{tabular}

Blinding (performance bias and detection Unclear risk bias)

Objective measures

Incomplete outcome data (attrition bias) Low risk

Patient reported measures

\begin{tabular}{l|l|l}
\hline $\begin{array}{l}\text { Incomplete outcome data (attrition bias) } \\
\text { Objective measures }\end{array}$ & Low risk & None. \\
\hline Selective reporting (reporting bias) & Unclear risk & No protocol available. \\
\hline Other bias & Low risk & Smoking status not reported. \\
\hline $\begin{array}{l}\text { Selection bias (imbalance in baseline char- } \\
\text { acteristics) }\end{array}$ & Unclear risk & \\
\hline
\end{tabular}

Heckman 1994

\begin{tabular}{ll}
\hline Methods & Randomised, placebo-controlled study. \\
\hline Participants & $\begin{array}{l}\text { Setting: University of Texas Health Science Centre, USA. } \\
\text { Size: } 97 \text { patients were enrolled. Of the } 48 \text { patients in the test group, } 11 \text { violated the } \\
\text { protocol and } 4 \text { were lost to follow-up, leaving } 33 \text { patients completing the study. Of the } \\
49 \text { patients in the control group, } 6 \text { violated the protocol and } 9 \text { were lost to follow up, } \\
\text { leaving } 34 \text { patients completing the study } \\
\text { Baseline characteristics: mean age was } 36 \text { years, with } 25 \text { males and } 8 \text { females in the } \\
\text { intervention group, and mean age } 31 \text { years with } 29 \text { males to } 5 \text { females in the control }\end{array}$
\end{tabular}

Quote: "The patients were randomly provided with either an active or sham ultrasound device in a double-blind manner"

Comment: Likely to be the same device but placebo devices were deactivated

No patient reported outcome measures. 
Heckman 1994 (Continued)

group
Inclusion criteria: skeletally mature men and non-pregnant women aged less than 76
years with closed or grade I open, transverse or short oblique/spiral, fractures of the tibial
diaphysis that could be treated with closed reduction and cast immobilisation
Exclusion criteria: post-reduction findings of long oblique/spiral fracture, length of frac-
ture line greater than twice the diameter of the diaphysis; fracture displacement greater
than $50 \%$; fracture gap greater than $0.5 \mathrm{~cm}$ or persistent shortening; persistent angula-
tion greater than 10 degrees; metaphyseal fracture; large butterfly fragment; pathological
fracture; comminution; participant inability to comply with trial procedures; current
prescription of NSAID, calcium channel blockers, bisphosphonates; history of throm-
bophlebitis, vascular insufficiency, alcoholism or nutritional deficiency

Interventions

Participants were treated with closed reduction and above-knee casting. An alignment window was placed in the cast at the level of the fracture over the antero-medial aspect of the leg. Reduction of the casting to a below-knee cast, any subsequent splintage and weight bearing status was at the discretion of the clinician

Test: participants underwent ultrasound treatment for 20 minutes each day from the second to twentieth week, or earlier if the clinician believed there was adequate evidence of union. The ultrasound signal was composed of a $200 \mu$ s burst of $1.5 \mathrm{MHz}$ sine waves, with a repetition rate of $1 \mathrm{kHz}$ and a spatial average intensity of $30 \mathrm{~mW} / \mathrm{cm}^{2}$

Control: participants in the control group were given a similar treatment regimen but had an externally similar sham machine instead

Outcomes

Follow-up schedule: plain radiographs at 4, 6, 8, 10, 12, 14, 20, 33 and 52 weeks. Clinical examination at times of cast change and at the time of union

Outcomes: time to combined radiographic and clinical union.

\section{Notes}

The weight bearing status of the patients was strictly described initially but subsequently handed over to the discretion of the treating clinician part way through the trial It was confirmed in personal communication with James Heckman that there was no time to union data on participants who violated protocol

Cook 1997 describes a subgroup analysis of the study by Heckman 1994. Smoking status was collected prospectively during the study for half the participants and retrospectively for the other half. There were 33 participants in the active group and 34 in the control group. These numbers correspond with the numbers of participants that successfully completed the study by Heckman 1994. Of these smoking status was not determined in 7 participants due to loss to follow-up

Risk of bias

\begin{tabular}{lll}
\hline Bias & Authors' judgement & Support for judgement \\
\hline $\begin{array}{l}\text { Random sequence generation (selection } \\
\text { bias) }\end{array}$ & Low risk & $\begin{array}{l}\text { Quote: “...predetermined computer gener- } \\
\text { ated code." } \\
\text { Comment: Likely to have been a robust } \\
\text { method. }\end{array}$
\end{tabular}


Heckman 1994 (Continued)

\begin{tabular}{|c|c|c|}
\hline Allocation concealment (selection bias) & Low risk & $\begin{array}{l}\text { Quote: "...the patients were randomized, in } \\
\text { groups of four, at each study site..." } \\
\text { Comment: It is likely that the sequence was } \\
\text { held centrally and allocations were given to } \\
\text { the distant study centres }\end{array}$ \\
\hline $\begin{array}{l}\text { Blinding (performance bias and detection } \\
\text { bias) } \\
\text { Patient reported measures }\end{array}$ & Low risk & None reported. \\
\hline $\begin{array}{l}\text { Blinding (performance bias and detection } \\
\text { bias) } \\
\text { Objective measures }\end{array}$ & Low risk & $\begin{array}{l}\text { Quote: "The active and placebo devices were } \\
\text { identical in every way..." } \\
\text { Comment: Likely to have been a robust } \\
\text { method. }\end{array}$ \\
\hline $\begin{array}{l}\text { Incomplete outcome data (attrition bias) } \\
\text { Patient reported measures }\end{array}$ & Low risk & None reported. \\
\hline $\begin{array}{l}\text { Incomplete outcome data (attrition bias) } \\
\text { Objective measures }\end{array}$ & Unclear risk & $\begin{array}{l}\text { Quote: “...patients who adhered to the study } \\
\text { protocol ... inferences were drawn" } \\
\text { Only data from } 67 \text { fractures were presented, } \\
\text { which represents a loss to follow-up of } 31 \% \text {. } \\
\text { [From JDH: } 13 \text { lost to follow-up, } 17 \text { did not } \\
\text { present in a timely manner so only certainty } \\
\text { is ultimate successful union, no time to event } \\
\text { data available.] }\end{array}$ \\
\hline Selective reporting (reporting bias) & Unclear risk & No protocol available. \\
\hline Other bias & High risk & $\begin{array}{l}\text { Quote: "Ninety-six patients, who had ... } \\
\text { ninety-seven fractures..." } \\
\text { Comment: Per protocol analysis only. Also, } \\
\text { there was no adjustment for recruiting related } \\
\text { fractures }\end{array}$ \\
\hline $\begin{array}{l}\text { Selection bias (imbalance in baseline char- } \\
\text { acteristics) }\end{array}$ & Unclear risk & $\begin{array}{l}\text { Smoking status is not reported as part of the } \\
\text { baseline characteristics of the participants }\end{array}$ \\
\hline
\end{tabular}

\section{Kristiansen 1997}

Methods

Participants

Randomised, placebo-controlled study.

Setting: multi-centre trial, USA.

Size: a total of 85 fractures in 83 patients. Of the 40 fractures in the test group, there were 10 withdrawn, leaving 30 . Of the 45 fractures in the control group, 3 were lost to follow-up and 11 were withdrawn, leaving 31

Baseline characteristics: there were 6 males and 24 females in the intervention group and 4 males and 27 females in the control group 
Kristiansen 1997 (Continued)

Inclusion: men and non-pregnant women who were at least 20 years old, who had closed
dorsally angulated metaphyseal fractures of the distal radius
Exclusion: fracture extending beyond $4 \mathrm{~cm}$ proximally from the tip of the radial styloid,
failure to satisfactorily reduce closed and immobilise in a below elbow cast, requirement
for additional reduction after ultrasound treatment had begun, associated fracture of
the ulnar shaft, current prescription of steroids or anticoagulant, any medical history of
thrombophlebitis or vascular insuffiencey of the upper limb, current nutritional defi-
ciency or alcohol dependency

Interventions

Patients underwent closed reduction and immobilisation of the limb in a cast with volar flexion and ulnar deviation. A window was created on the dorsal aspect of the cast overlying the fracture and a retaining alignment fixture was placed in the window. The patients were given a device within 7 days of the fracture, were told to use it for 20 minutes a day, until their 10 week appointment

Test: ultrasound probe that fitted into the retaining fixture was given to each participant. The ultrasound signal was composed of a $200 \mu$ surst of $1.5 \mathrm{MHz}$ sine waves, with a repetition rate of $1 \mathrm{kHz}$ and a spatial average intensity of $30 \mathrm{~mW} / \mathrm{cm}^{2}$

Control: a visually and audibly similar device was given to each participant

Outcomes

Follow-up schedule was weekly until week 6 and then 8, 10, 12 and 16 weeks. End point was defined as combined clinical and radiographic healing

Primary: time to radiographic union.

Secondary: time to early trabecular healing, time to cortical bridging, percentage of organised trabecular healing, loss of reduction

Notes

The protocol specified combined clinical and radiographic healing, but investigators were reluctant to remove casts, therefore no clinical data are reported and radiographic union was used as the primary outcome measure

It was confirmed in personal communication with Joan McCabe that multiple reports with similar titles were all from the same study

Cook 1997 describes a subgroup analysis of the study by Kristiansen 1997. Smoking status before and during the study was retrospectively collected. There were 30 participants in the active group and 31 in the control group. These numbers correspond with the numbers of participants that successfully completed the study by Kristiansen 1997. There were 10 participants who could not be located for a retrospective analysis of smoking status

Risk of bias

$\begin{array}{lll}\text { Bias Authors' judgement } & \text { Support for judgement }\end{array}$

Random sequence generation (selection Low risk bias)

Allocation concealment (selection bias)

Unclear risk
Quote: "Randomly assigned....according to a computer generated code, developed by an independent consultant"

Comments: Concealment of the codes is not reported. 
Kristiansen 1997 (Continued)

\begin{tabular}{|c|c|c|}
\hline $\begin{array}{l}\text { Blinding (performance bias and detection } \\
\text { bias) } \\
\text { Patient reported measures }\end{array}$ & Low risk & No patient reported measures. \\
\hline $\begin{array}{l}\text { Blinding (performance bias and detection } \\
\text { bias) } \\
\text { Objective measures }\end{array}$ & Low risk & $\begin{array}{l}\text { Quote: "The placebo device...was identical } \\
\text { to the active unit". "The principle investi- } \\
\text { gator and the independent radiologist...were } \\
\text { blinded...performed independent central as- } \\
\text { sessments...of the radiographic parameters of } \\
\text { union }\end{array}$ \\
\hline
\end{tabular}

Incomplete outcome data (attrition bias) Low risk

No patient reported measure.

Patient reported measures

Incomplete outcome data (attrition bias) High risk

Objective measures

Comments: The protocol specified combined clinical and radiographic healing, but investigators were reluctant to remove casts, therefore no clinical data is reported. All patients lost to follow-up accounted for but approximately $30 \%$ loss to follow-up

\begin{tabular}{|c|c|c|}
\hline Selective reporting (reporting bias) & Unclear risk & No protocol available. \\
\hline Other bias & High risk & $\begin{array}{l}\text { Two patients had bilateral fractures and they } \\
\text { were treated with alternate devices. These frac- } \\
\text { tures were analysed as independent events }\end{array}$ \\
\hline $\begin{array}{l}\text { Selection bias (imbalance in baseline char- } \\
\text { acteristics) }\end{array}$ & Unclear risk & $\begin{array}{l}\text { Gender, age and fracture characteristics were } \\
\text { similar. Smoking status is not reported }\end{array}$ \\
\hline
\end{tabular}

\section{Leung 2004}

\begin{tabular}{ll} 
Methods & Quasi-randomised, placebo-controlled study. \\
\hline Participants & $\begin{array}{l}\text { Setting: Chinese University of Hong Kong, China. } \\
\text { Size: a total of } 30 \text { fractures in } 28 \text { patients. The test group had } 16 \text { fractures in } 15 \text { patients } \\
\text { and the control group had } 14 \text { fractures in } 13 \text { patients } \\
\text { Baseline characteristics: mean (range) age } 35.3 \text { years }(22 \text { to } 61), 25 \text { males and } 3 \text { females } \\
\text { Inclusion: patients with open or comminuted tibial fractures } \\
\text { Exclusion: simple fractures, fractures of sites other than the tibia }\end{array}$ \\
\hline Interventions & $\begin{array}{l}\text { Patients with closed fractures or Gustillo grade } 1 \text { or } 2 \text { open fractures in the diaphysis } \\
\text { underwent fixation with reamed, locked intramedullary nail. Participants with fractures } \\
\text { in the metaphysis or Gustillo grade } 3 \text { open fractures were treated with an external fixator. } \\
\text { All open fractures were treated with emergency debridement and delayed closure } \\
\text { Test: LIPUS machine was given to the patients as soon as the soft tissues were closed. } \\
\text { The ultrasound signal was composed of a } 200 \mu \text { burst of } 1.5 \text { MHz sine waves, with a }\end{array}$ \\
\hline
\end{tabular}


repetition rate of $1 \mathrm{kHz}$ and a spatial average intensity of $30 \mathrm{~mW} / \mathrm{cm}^{2}$ and was given for 20 minutes a day, for 90 days using coupling gel applied directly over the fracture site Control: a sham device that was externally identical to the LIPUS machine was given to the participants as soon as the soft tissues were closed

Outcomes

Notes
End point was combined clinical and radiographic union. Clinical union was defined as full painless weightbearing. Radiographic union was defined as 3 out of 4 cortices were bridged with bone on plain orthogonal radiograph. Follow-up times were every 3 weeks for the first 3 months, every 6 weeks for the following 3 months and every 8 weeks for the last 6 months. The radiographs were assessed by 3 independent surgeons and a mean time of union was used

Primary: time to union.

Secondary: bone mineral density and plasma bone specific alkaline phosphatase, adverse events

\section{Risk of bias}

\begin{tabular}{lll}
\hline Bias & Authors' judgement & Support for judgement \\
\hline $\begin{array}{l}\text { Random sequence generation (selection } \\
\text { bias) }\end{array}$ & High risk & $\begin{array}{l}\text { Quote: “...assigned...according to the se- } \\
\text { quence of admission” } \\
\text { Comments: Quasi-randomised. }\end{array}$ \\
\hline Allocation concealment (selection bias) & High risk & $\begin{array}{l}\text { Quote: “...assigned...according to the se- } \\
\text { quence of admission” } \\
\text { Comments: No list provided. Quasi-ran- } \\
\text { domised. }\end{array}$ \\
\hline
\end{tabular}

Blinding (performance bias and detection Low risk bias)

None reported.

Patient reported measures

Blinding (performance bias and detection High risk bias)

Objective measures
Quote: "Control group were given a dummy machine".

Comments: Efforts were made to blind the patients, but the assessors were not blind as the machines were not identical and the patients were quasi-randomly allocated

None reported.

Incomplete outcome data (attrition bias) Low risk Patient reported measures

Incomplete outcome data (attrition bias) Low risk Objective measures

\begin{tabular}{lll}
\hline Selective reporting (reporting bias) & Unclear risk & No protocol available.
\end{tabular}

The complete dataset was presented.

No protocol available. 


\begin{tabular}{|c|c|c|}
\hline Other bias & High risk & $\begin{array}{l}\text { Quote: "Four patients had segmental frac- } \\
\text { tures..." } \\
\text { Some participants had two fractures which } \\
\text { may have been randomised independently. } \\
\text { No statistical adjustments were reported to } \\
\text { allow for this }\end{array}$ \\
\hline
\end{tabular}

\section{Lubbert 2008}

\begin{tabular}{ll}
\hline Methods & Randomised, placebo-controlled study. \\
\hline Participants & $\begin{array}{l}\text { Setting: multi-centre trial, Netherlands. } \\
\text { Size: there were } 120 \text { patients. Of the } 61 \text { in the test group, } 9 \text { were lost to follow-up, } \\
\text { leaving } 52 \text { patients. Of the } 59 \text { in the control group, } 7 \text { were lost to follow-up and } 3 \text { did } \\
\text { not complete the intervention, leaving } 49 \text { patients } \\
\text { Baseline characteristics: } 46 \text { males and } 6 \text { females in the intervention group and } 39 \text { males } \\
\text { and } 10 \text { females in the control group } \\
\text { Inclusion: over } 18 \text { years of age, diaphyseal fracture of the clavicle (Allman group 1), } \\
\text { treatment begun within } 5 \text { days of trauma } \\
\text { Exclusion: multiple trama, re-fracture, pathological fracture, open fracture or threatened } \\
\text { soft tissue envelope, metaphyseal fracture }\end{array}$ \\
\hline
\end{tabular}

Interventions

All participants were treated non-operatively with a collar and cuff sling for symptom control. Free arm movements within a range allowed by pain were allowed from day 1 . Participants maintained a treatment diary

Test: a LIPUS machine was given to the patients at the first visit. The ultrasound signal was given for 20 minutes a day, for 28 days using coupling gel applied directly over the fracture site. The unit was an Exogen 2000 battery powered Main Operating Unit and a Smith and Nephew Treatment Head Module transducer that delivered an ultrasound signal composed of a $200 \mu$ s burst of $1.5 \mathrm{MHz}$ sine waves, with a repetition rate of 1 $\mathrm{kHz}$ and a spatial average intensity of $30 \mathrm{~mW} / \mathrm{cm}^{2}$

Control: a sham device that was externally identical to the LIPUS machine was given to the participants with similar instructions for use

Outcomes

Follow-up schedule: 1, 2, 4, 6, 8 weeks.

Primary: patient reported subjective clinical fracture healing

Secondary: Pain (VAS and painkiller use), operation, adverse events, resumption of sport/ professional activities/sport

Data from the patients excluded from the study was provided by Pieter Lubbert in personal communication; these allowed an intention-to-treat analysis

\section{Risk of bias}

\begin{tabular}{|c|c|c|}
\hline Bias & Authors' judgement & Support for judgement \\
\hline
\end{tabular}




\section{Lubbert 2008 (Continued)}

\begin{tabular}{l|l|l}
$\begin{array}{l}\text { Random sequence generation (selection } \\
\text { bias) }\end{array}$ & Low risk & $\begin{array}{l}\text { Quote: "For each participating hospital con- } \\
\text { secutive numbered transducers were delivered } \\
\text { in packs of four." } \\
\text { "Randomisation took place at the site of the } \\
\text { manufacturer." } \\
\text { Comment: Distant block randomisation. }\end{array}$ \\
\hline Allocation concealment (selection bias) & Low risk & $\begin{array}{l}\text { Quotes: "Each hospital supply contained two } \\
\text { randomly assigned active transducers and two } \\
\text { placebo transducers." } \\
\text { "The placebo transducers looked identical..." } \\
\text { Comment: Allocation was concealed at a dis- } \\
\text { tant site. }\end{array}$ \\
\hline
\end{tabular}

Blinding (performance bias and detection Low risk

bias)

Quote: "The placebo transducers looked

Patient reported measures

identical..."

Blinding (performance bias and detection Low risk

bias)

Quote: "The placebo transducers looked

Objective measures

identical..."

Incomplete outcome data (attrition bias) High risk

Trial flow diagram presented clearly. Only a

Patient reported measures

per-protocol analysis was presented

Incomplete outcome data (attrition bias) Low risk None reported.

Objective measures

\begin{tabular}{l|ll}
\hline Selective reporting (reporting bias) & Unclear risk & No protocol available. \\
\hline Other bias & Low risk & \\
\hline $\begin{array}{l}\text { Selection bias (imbalance in baseline char- } \\
\text { acteristics) }\end{array}$ & Unclear risk & $\begin{array}{l}\text { Age and smoking status not separately re- } \\
\text { ported. }\end{array}$ \\
\hline
\end{tabular}

\section{Mayr 2000}

Methods

Participants
Randomised controlled trial

Setting: German emergency outpatient department. Single centre study Size: 29 patients, 30 fractures; 15 fractures in each group.

Baseline characteristics: mean age (SD) age 37 (14) years; 5 to 1 male / female ratio Inclusion: skeletally mature adults with a fresh stable scaphoid fracture (AO B1 and B2) Exclusion: unstable fractures, generalised skeletal disease, pathological fracture, fracture more than 10 days old at diagnosis 


\begin{tabular}{ll} 
Interventions & $\begin{array}{l}\text { A forearm plaster splint was applied to include the thumb to the interphalangeal joint. } \\
\text { After detumescence, the splint was replaced with a circular restraining forearm bandage } \\
\text { to include the thumb to the interphalangeal joint } \\
\text { Test: after appliance of the circular immobilising forearm bandage, daily } 20 \text {-minute } \\
\text { pulsed low-intensity ultrasound treatment (SAFHS, Exogen, Piscataway, NJ, USA; fre- } \\
\left.\text { quency: } 1.5 \mathrm{MHz} \text {, pulsed with } 1 \mathrm{kHz} \text {, signal length: } 200 \mu \mathrm{sec} \text {, intensity: } 30 \mathrm{~mW} / \mathrm{cm}^{2}\right) \\
\text { was conducted } \\
\text { Control: no additional placebo treatment. }\end{array}$ \\
\hline Outcomes & $\begin{array}{l}\text { Follow-up schedule: CT at } 6 \text { weeks and then every } 2 \text { weeks until union. } \\
\text { Primary outcome: time to union by CT assessment of fracture union } \\
\text { Secondary outcome: percentage of ossification of the fracture gap }\end{array}$ \\
\hline Notes & $\begin{array}{l}\text { The follow-up schedule was changed after six patients had been scanned at } 6 \text { weeks, } \\
\text { when } 3 \text { of them had already achieved union. From that point onwards in the trial, first } \\
\text { follow-up was at } 4 \text { weeks } \\
\text { Translated from German. }\end{array}$ \\
\hline
\end{tabular}

\section{Risk of bias}

\begin{tabular}{|c|c|c|}
\hline Bias & Authors' judgement & Support for judgement \\
\hline $\begin{array}{l}\text { Random sequence generation (selection } \\
\text { bias) }\end{array}$ & Low risk & Sequence generated by a random number generator. \\
\hline Allocation concealment (selection bias) & Unclear risk & Not reported. \\
\hline $\begin{array}{l}\text { Blinding (performance bias and detection } \\
\text { bias) } \\
\text { Patient reported measures }\end{array}$ & Unclear risk & No patient reported measures were recorded. \\
\hline $\begin{array}{l}\text { Blinding (performance bias and detection } \\
\text { bias) } \\
\text { Objective measures }\end{array}$ & Low risk & CT scans were blinded before reporting. \\
\hline $\begin{array}{l}\text { Incomplete outcome data (attrition bias) } \\
\text { Patient reported measures }\end{array}$ & Unclear risk & No patient reported measures were recorded. \\
\hline $\begin{array}{l}\text { Incomplete outcome data (attrition bias) } \\
\text { Objective measures }\end{array}$ & Low risk & There was no loss of outcome data. \\
\hline Selective reporting (reporting bias) & Unclear risk & No protocol available. \\
\hline Other bias & Low risk & \\
\hline $\begin{array}{l}\text { Selection bias (imbalance in baseline char- } \\
\text { acteristics) }\end{array}$ & Unclear risk & Smoking status is not reported. \\
\hline
\end{tabular}




\begin{tabular}{ll}
\hline Methods & Randomised, placebo-controlled trial \\
\hline Participants & $\begin{array}{l}\text { Setting: US Naval Academy } \\
\text { Size: } 40 \text { midshipmen with } 58 \text { stress fractures; data reported for } 26 \text { (14 in the treatment } \\
\text { group and } 12 \text { in the control group) midshipmen with tibial stress fractures } \\
\text { Baseline characteristics: } 23 \text { men and } 17 \text { women; mean age } 19 \text { years; fractures sites were } \\
\text { tibia, metatarsal, femur and fibula (74\%, } 9 \%, 5 \% \text { and } 5 \% \text { respectively) } \\
\text { Inclusion: new midshipmen sustaining stress fractures diagnosed on radiographic and } \\
\text { scintigraphic examinations during initial training. Informed consent. } \\
\text { Exclusion: none }\end{array}$ \\
\hline Interventions & $\begin{array}{l}\text { While not stated explicitly it is likely that all participants received the standard-of-care } \\
\text { treatment that included protected weight bearing if normal walking reproduced symp- } \\
\text { toms, alternative aerobic exercise, a daily multivitamin and calcium supplementation } \\
\text { (twice daily } 500 \text { mg) } \\
\text { Test: daily } 20 \text {-minute LIPUS treatment (Exogen Inc, Piscataway, NJ) administered by } \\
\text { sports medicine personnel until stress fracture had healed } \\
\text { Control: similar protocol with a sham unit. }\end{array}$ \\
\hline $\begin{array}{l}\text { Follow-up schedule: daily treatments until fit to return to duty (work) defined as no pain } \\
\text { on palpation, the ability to do a single leg hop on the affected side without pain and } \\
\text { radiographic evidence of healing } \\
\text { Primary outcome: time to return to duty (work) } \\
\text { Secondary outcome: adherence }\end{array}$ \\
\hline Outcomes
\end{tabular}

Although 40 participants were enrolled with a variety of injured bones only 33 were able to comply with the protocol for a variety of reasons. Of these 33,7 further participants were excluded from the analysis as only those with fractures of the tibia were analysed (total attrition: 14 of 40). The 26 participants had 43 tibial stress fractures - time to return to duty was based on stress fracture site with the longest duration of symptoms

\section{Risk of bias}

\begin{tabular}{|c|c|c|}
\hline Bias & Authors' judgement & Support for judgement \\
\hline $\begin{array}{l}\text { Random sequence generation (selection } \\
\text { bias) }\end{array}$ & Unclear risk & $\begin{array}{l}\text { Quote: “....and were randomized into one of two } \\
\text { treatment protocols..." } \\
\text { Comment: No description of sequence genera- } \\
\text { tion. }\end{array}$ \\
\hline Allocation concealment (selection bias) & Unclear risk & $\begin{array}{l}\text { Quote: “...and were randomized into one of two } \\
\text { treatment protocols..." } \\
\text { Comment: No description of allocation con- } \\
\text { cealment. }\end{array}$ \\
\hline
\end{tabular}

Blinding (performance bias and detection Low risk bias)

Patient reported measures
Quote: "The placebo group underwent the identical protocol, except that the stimulator unit was non-functional. This study was a double-blind, placebo-controlled investigation." 


\begin{tabular}{|c|c|c|}
\hline & & $\begin{array}{l}\text { Comment: Participants were blinded to inter- } \\
\text { vention. }\end{array}$ \\
\hline $\begin{array}{l}\text { Blinding (performance bias and detection } \\
\text { bias) } \\
\text { Objective measures }\end{array}$ & Unclear risk & $\begin{array}{l}\text { Quote: "This study was a double-blind ... in- } \\
\text { vestigation." } \\
\text { Comment: Trial personnel administered the } \\
\text { treatments and documented adherence. It is not } \\
\text { explicit that they were also blind to the alloca- } \\
\text { tion although the study was 'double-blind' }\end{array}$ \\
\hline $\begin{array}{l}\text { Incomplete outcome data (attrition bias) } \\
\text { Patient reported measures }\end{array}$ & High risk & $\begin{array}{l}\text { Overall attrition proportion was } 14 \text { of } 40 \text { and } \\
\text { the loss was explicitly systematic }\end{array}$ \\
\hline $\begin{array}{l}\text { Incomplete outcome data (attrition bias) } \\
\text { Objective measures }\end{array}$ & High risk & $\begin{array}{l}\text { Overall attrition proportion was } 14 \text { of } 40 \text { and } \\
\text { the loss was explicitly systematic }\end{array}$ \\
\hline Selective reporting (reporting bias) & Unclear risk & No protocol available. \\
\hline Other bias & Low risk & \\
\hline $\begin{array}{l}\text { Selection bias (imbalance in baseline char- } \\
\text { acteristics) }\end{array}$ & Unclear risk & Smoking status is not reported. \\
\hline
\end{tabular}

\section{Strauss 1999}

\begin{tabular}{ll}
\hline Methods & Randomised controlled trial \\
\hline Participants & $\begin{array}{l}\text { Setting: USA hospital. } \\
\text { Size: } 20 \text { participants, } 20 \text { fractures; } 10 \text { fractures in each group } \\
\text { Baseline characteristics: not reported. } \\
\text { Inclusion: patients with a fracture of the fifth metatarsal (zone II) } \\
\text { Exclusion: not stated }\end{array}$ \\
\hline Interventions & $\begin{array}{l}\text { All fractures were initially treated with short leg cast and weightbearing as tolerated for } \\
\text { a mean of } 10 \text { days. All casts were converted to a hinged ankle foot orthosis and patients } \\
\text { continued with weightbearing until fracture union } \\
\text { Test: participants were given LIPUS therapy for } 20 \text { minutes twice each day } \\
\text { Control: participants were given no additional placebo treatment. }\end{array}$ \\
\hline Outcomes & $\begin{array}{l}\text { Follow-up schedule: not reported. } \\
\text { Primary: time to clinical and radiographic union. } \\
\text { Secondary: proportion of union within } 20 \text { weeks. }\end{array}$ \\
\hline Notes & $\begin{array}{l}\text { Inadequate data were presented to include the primary outcome in the analysis in this } \\
\text { review }\end{array}$ \\
\hline
\end{tabular}

\section{Risk of bias}


Strauss 1999 (Continued)

\begin{tabular}{|c|c|c|}
\hline Bias & Authors' judgement & Support for judgement \\
\hline $\begin{array}{l}\text { Random sequence generation (selection } \\
\text { bias) }\end{array}$ & Unclear risk & $\begin{array}{l}\text { Quote: “...were studied in a prospective randomized set- } \\
\text { ting. The twenty fractures were randomly divided..." } \\
\text { Comment: Method of randomisation is unclear. }\end{array}$ \\
\hline Allocation concealment (selection bias) & Unclear risk & $\begin{array}{l}\text { Quote: “...were studied in a prospective randomized set- } \\
\text { ting. The twenty fractures were randomly divided..." } \\
\text { Comment: Method of randomisation is unclear. }\end{array}$ \\
\hline $\begin{array}{l}\text { Blinding (performance bias and detection } \\
\text { bias) } \\
\text { Patient reported measures }\end{array}$ & Unclear risk & None reported. \\
\hline $\begin{array}{l}\text { Blinding (performance bias and detection } \\
\text { bias) } \\
\text { Objective measures }\end{array}$ & High risk & $\begin{array}{l}\text { Quote: “...Group B (control or no ultrasound treatment) } \\
. ” \\
\text { Comment: Control group received no sham LIPUS ma- } \\
\text { chine. }\end{array}$ \\
\hline $\begin{array}{l}\text { Incomplete outcome data (attrition bias) } \\
\text { Patient reported measures }\end{array}$ & Low risk & None reported. \\
\hline $\begin{array}{l}\text { Incomplete outcome data (attrition bias) } \\
\text { Objective measures }\end{array}$ & Unclear risk & $\begin{array}{l}\text { All participants were followed up to the final time point } \\
\text { of the study }\end{array}$ \\
\hline Selective reporting (reporting bias) & Unclear risk & No protocol available. \\
\hline Other bias & High risk & $\begin{array}{l}\text { This study was only reported as a poster abstract. The } \\
\text { detail contained within this report is minimal and eval- } \\
\text { uation of the risk of bias is extremely limited }\end{array}$ \\
\hline $\begin{array}{l}\text { Selection bias (imbalance in baseline char- } \\
\text { acteristics) }\end{array}$ & Unclear risk & Baseline characteristics were not reported. \\
\hline
\end{tabular}

Wang 2007

\begin{tabular}{ll}
\hline Methods & Quasi-randomised controlled trial \\
\hline Participants & Setting: Taiwan \\
& Size: a total of 59 fractures in 56 patients. There was one exclusion in each group, leading \\
to 27 fractures in 27 patients in the test and 30 fractures in 27 patients in the control \\
Baseline characteristics: mean (range) age was 34.2 years (15 to 81$), 40$ males and 16 \\
females \\
$\begin{array}{l}\text { Inclusion: patients with acute, displaced, high energy trauma diaphyseal fractures of the } \\
\text { femur and tibia that required reduction and internal or external fixation } \\
\text { Exclusion: pathological fracture, active infection, coagulopathy, immunosuppression, } \\
\text { pregnancy, cardiac pacemaker, skeletal immaturity, poor compliance }\end{array}$
\end{tabular}




$\begin{array}{ll}\text { Interventions } & \text { All closed fractures were treated with open or closed reduction and internal fixation with } \\ \text { intra-medullary nailing or plate fixation. Patients with type III-C open fractures were } \\ \text { initially treated with surgical debridement of the wounds and external fixator for fracture } \\ \text { stabilization. Delayed open or closed reduction and internal fixation was performed } \\ \text { when the soft tissues were optimised. All other open fractures were treated with primary } \\ \text { open reduction and internal fixation } \\ \text { Postoperative management included early ambulation with no weight bearing allowed } \\ \text { through the affected limb; quadriceps and hamstring and lower limb joint range of } \\ \text { motion exercises } \\ \text { Test: participants in the study group received shockwave treatment immediately after } \\ \text { surgery under the same anaesthesia. For patients with type III-C open fractures, shock- } \\ \text { wave treatment was performed after delayed open reduction and internal fixation for the } \\ \text { fractures. The source of shockwaves was from an OssaTron (High Medical Technology, } \\ \text { Kreulingen, Switzerland). Shockwaves were performed with patients on the fracture ta- } \\ \text { ble. The fracture site was verified with C-arm X-rays, and the depth of treatment was } \\ \text { confirmed with the control guide of the device under C-arm imaging. Surgical lubrica- } \\ \text { tion gel was applied to the area of skin in direct contact with the shockwave tube. Each } \\ \text { fracture site was treated with } 6,000 \text { impulses of shockwave at } 28 \mathrm{kV} \text { (equivalent to } 0.62 \\ \text { mJ/mm }{ }^{2} \text { energy flux density). Shockwaves were applied in two planes with equal dosage } \\ \text { in each plane as a single session } \\ \text { Control: participants in the control group received open reduction and internal fixation } \\ \text { without shockwave treatment after surgery }\end{array}$

Outcomes

Follow-up schedule: 1, 3, 6 and 12 months.

Primary: proportion of union at 12 months.

Secondary: proportion of union at earlier time points, fracture alignment, pain (VAS), weight bearing status, adverse events

Notes

Authors have assumed independence between observations from multiple fractures in a single participant

\section{Risk of bias}

\begin{tabular}{|c|c|c|}
\hline Bias & Authors' judgement & Support for judgement \\
\hline $\begin{array}{l}\text { Random sequence generation (selection } \\
\text { bias) }\end{array}$ & High risk & $\begin{array}{l}\text { Quote: "[The study group] who had surgery on } \\
\text { odd days of the week, and the control group ... who } \\
\text { had surgery performed on even days of the week" } \\
\text { Comment: Quasi-randomised study. }\end{array}$ \\
\hline Allocation concealment (selection bias) & High risk & $\begin{array}{l}\text { Quote: "[The study group] who had surgery on } \\
\text { odd days of the week, and the control group..who } \\
\text { had surgery performed on even days of the week" } \\
\text { Comment: Unclear whether method of randomi- } \\
\text { sation known, but would be easy to identify pat- } \\
\text { tern }\end{array}$ \\
\hline
\end{tabular}


Wang 2007 (Continued)

\begin{tabular}{l|l}
$\begin{array}{l}\text { Blinding (performance bias and detection } \\
\text { bias) } \\
\text { Patient reported measures }\end{array}$ & $\begin{array}{l}\text { Quote: "Patients in the control group ... without } \\
\text { shockwave treatment after surgery." } \\
\text { Comment: It is not reported whether the partici- } \\
\text { pants were blind to their allocation }\end{array}$ \\
\hline
\end{tabular}

Blinding (performance bias and detection Low risk bias)

Objective measures

Quote: “An independent examiner blinded to the nature of the study protocol performed the examination."

\begin{tabular}{l|l}
$\begin{array}{l}\text { Incomplete outcome data (attrition bias) } \\
\text { Patient reported measures }\end{array}$ & High risk
\end{tabular}$\quad \begin{aligned} & \begin{array}{l}\text { Quote: "Two patients were excluded from the fi- } \\
\text { nal analysis because of postoperative deep infection } \\
\text { and osteomyelitis." }\end{array} \\
& \begin{array}{l}\text { Comment: This was consistent with the eligibility } \\
\text { criteria but is an unusual means to handle data from } \\
\text { participants developing adverse events }\end{array}\end{aligned}$

Incomplete outcome data (attrition bias) High risk $\quad$ Quote: "Two patients were excluded from the fiObjective measures nal analysis because of postoperative deep infection and osteomyelitis."

Comment: This was consistent with the eligibility criteria but is an unusual means to handle data from participants developing adverse events

\begin{tabular}{|c|c|c|}
\hline Selective reporting (reporting bias) & Unclear risk & No protocol available. \\
\hline Other bias & Low risk & $\begin{array}{l}\text { Quote: "56 patients with } 59 \text {... fractures" } \\
\text { Some participants had two fractures which may } \\
\text { have been randomised independently. No statisti- } \\
\text { cal adjustments were reported to allow for this }\end{array}$ \\
\hline $\begin{array}{l}\text { Selection bias (imbalance in baseline char- } \\
\text { acteristics) }\end{array}$ & Unclear risk & $\begin{array}{l}\text { The distribution of smoking status between the } \\
\text { groups is not reported }\end{array}$ \\
\hline
\end{tabular}

Yadav 2008

\begin{tabular}{ll}
\hline Methods & Randomised, placebo-controlled trial \\
\hline Participants & Setting: Indian military recruits in training. \\
& Size: 67 cases with stress fracture; with 39 in the treatment group and 28 in the control \\
& group \\
& Baseline characteristics: age not reported, gender data not reported \\
& Inclusion: history and examination consistent with a diagnosis of stress fracture \\
& Exclusion: none. \\
\hline
\end{tabular}

Interventions

All participants were managed non-operatively and prescribed paracetamol and ice-packs Test: treated with $10 \mathrm{~min} /$ day using a ultrasound probe emitting a $3 \mathrm{MHz}, 1 \mathrm{~W} / \mathrm{cm}^{2}$ ultrasound signal pulsed with a duty cycle of $50 \%$

Control: similar treatment with a sham unit which was identical to the test unit 
Yadav 2008 (Continued)

\begin{tabular}{|c|c|c|}
\hline Outcomes & \multicolumn{2}{|c|}{ Time to return to training. No radiological outcome measures assessed } \\
\hline \multicolumn{3}{|l|}{ Notes } \\
\hline \multicolumn{3}{|l|}{ Risk of bias } \\
\hline Bias & Authors' judgement & Support for judgement \\
\hline $\begin{array}{l}\text { Random sequence generation (selection } \\
\text { bias) }\end{array}$ & Low risk & $\begin{array}{l}\text { Quote: “...were randomly assigned ... by chit } \\
\text { method." }\end{array}$ \\
\hline Allocation concealment (selection bias) & Unclear risk & $\begin{array}{l}\text { Quote: “...were randomly assigned ... by chit } \\
\text { method." } \\
\text { Comment: It is not clear whether this was done } \\
\text { on or off site and who had access to the results }\end{array}$ \\
\hline $\begin{array}{l}\text { Blinding (performance bias and detection } \\
\text { bias) } \\
\text { Patient reported measures }\end{array}$ & Low risk & $\begin{array}{l}\text { Quotes: “... nonfunctioning unit identical in } \\
\text { appearance.” } \\
\text { “... patients ... study’s researchers were blinded. } \\
. . ”\end{array}$ \\
\hline $\begin{array}{l}\text { Blinding (performance bias and detection } \\
\text { bias) } \\
\text { Objective measures }\end{array}$ & Low risk & $\begin{array}{l}\text { Quotes: “... nonfunctioning unit identical in } \\
\text { appearance." } \\
\text { “... patients ... study's researchers were blinded. } \\
. . ”\end{array}$ \\
\hline $\begin{array}{l}\text { Incomplete outcome data (attrition bias) } \\
\text { Patient reported measures }\end{array}$ & Low risk & There were no missing data. \\
\hline $\begin{array}{l}\text { Incomplete outcome data (attrition bias) } \\
\text { Objective measures }\end{array}$ & Low risk & There were no missing data. \\
\hline Selective reporting (reporting bias) & Unclear risk & No protocol available. \\
\hline Other bias & Low risk & \\
\hline $\begin{array}{l}\text { Selection bias (imbalance in baseline char- } \\
\text { acteristics) }\end{array}$ & Unclear risk & $\begin{array}{l}\text { Quote: “... matched in terms of age, height, de- } \\
\text { mographics, and delay from symptom onset to } \\
\text { diagnosis." } \\
\text { Comment: Sex and smoking status not re- } \\
\text { ported. }\end{array}$ \\
\hline
\end{tabular}

$\mathrm{CT}=$ computed tomography

LIPUS = low intensity pulsed ultrasound 
Characteristics of excluded studies [ordered by study ID]

\begin{tabular}{ll}
\hline Study & Reason for exclusion \\
\hline Basso 1998 & $\begin{array}{l}\text { This RCT involving a single application of ultrasound to conservatively treated distal radius fractures reported on } \\
\text { range of motion and referral for physiotherapy at } 8 \text { weeks. It is excluded because its focus was not on fracture } \\
\text { healing - it also not did not report any outcome measures pertinent to this review }\end{array}$ \\
\hline Busse 2005 & This study is a health economic analysis which is informed using data from a systematic review \\
\hline Heckman 1997 & $\begin{array}{l}\text { This study is a cost analysis based upon models developed from clinical data and specified assumptions. It is not a } \\
\text { formal health economics analysis within a randomised controlled trial }\end{array}$ \\
\hline
\end{tabular}

Characteristics of studies awaiting assessment [ordered by study ID]

\section{ISRCTN90844675}

\begin{tabular}{|c|c|}
\hline Methods & Randomised controlled multi-centre trial \\
\hline Participants & $\begin{array}{l}\text { Adults with closed or type I open fractures of the tibia that had been treated by reamed or unreamed locking } \\
\text { intramedullary nails less than } 10 \text { days prior to randomisation. Patients with fractures of the lateral malleolus, fixed } \\
\text { by plates, as well as patients with minor concomitant injuries (bruises, sprains) were offered trial participation } \\
\text { Intended target population: } 250\end{array}$ \\
\hline Interventions & $\begin{array}{l}\text { Test: pulsed, low-energetic ultrasound (Exogen, Smith \& Nephew), applied daily for three months } \\
\text { Control: standard of care }\end{array}$ \\
\hline Outcomes & $\begin{array}{l}\text { Follow-up: } 1 \text { year } \\
\text { Primary: bony union three months ( }+/-1 \text { week) after randomisation, as assessed on plain radiographs by independent, } \\
\text { blinded raters } \\
\text { Secondary (assessed after } 6 \text { weeks, } 3,6 \text {, and } 12 \text { months): } \\
\text { 1. Delayed union and non-union rates } \\
\text { 2. Health-related quality of life (36-item Short Form Health Survey [SF-36], EuroQoL instrument [EQ-5D]) } \\
\text { 3. Functional outcomes (Western Ontario and McMaster Universities Osteoarthritis Index [WOMAC]) } \\
\text { 4. Duration of sick leave } \\
\text { 5. Cost-utility } \\
\text { 6. Serious adverse events (SAE) }\end{array}$ \\
\hline Notes & $\begin{array}{l}\text { Trial registration identified after preparation of the review. Indicated as a completed trial }(01 / 10 / 2008 \text { to } 01 / 10 / \\
\text { 2010). Efforts to find out its current status are ongoing. } \\
\text { Contact: Dr Julia Seifert, Berlin (julia.seifert@ukb.de) }\end{array}$ \\
\hline
\end{tabular}




\section{TRUST (Pilot)}

\begin{tabular}{ll}
\hline Methods & Randomised controlled trial \\
\hline Participants & Patients with conservatively managed fractures of the tibia. Target population = 50 \\
\hline Interventions & $\begin{array}{l}\text { Test: LIPUS (low intensity pulsed ultrasound) - Exogen (Piscataway, New Jersey) Sonic Accelerated Fracture Healing } \\
\text { System } \\
\text { Control: Sham ultrasound unit }\end{array}$ \\
\hline Outcomes & $\begin{array}{l}\text { Primary: SF-36 } \\
\text { Secondary: } \\
\text { 1. Time to radiographic healing of tibial fractures } \\
\text { 2. Rates of malunion and non-union of tibial fractures } \\
\text { 3. Rates of secondary procedures (operative and non-operative) }\end{array}$ \\
\hline Notes & $\begin{array}{l}\text { This single-centre trial, funded by the Canadian Institutes of Health, is a pilot study for the other ongoing trial on } \\
\text { operatively managed tibia fractures. The study is complete (Busse 2011). The authors have provisionally agreed to } \\
\text { provide an unpublished manuscript for this Review once the Steering Committee have released it for submission for } \\
\text { publication in 2012 (Busse 2011). }\end{array}$ \\
\hline
\end{tabular}

Characteristics of ongoing studies [ordered by study ID]

TRUST (Full)

\begin{tabular}{ll}
\hline Trial name or title & Trial to re-evaluate ultrasound in the treatment of tibial fractures (TRUST) \\
\hline Methods & Randomised controlled trial \\
\hline Participants & Patients with tibial fractures treated with intramedullary nailing. Target population $=500$ \\
\hline Interventions & $\begin{array}{l}\text { Test: LIPUS (low intensity pulsed ultrasound) - Exogen (Piscataway, New Jersey) Bone Healing System } \\
\text { Control: Sham ultrasound unit }\end{array}$ \\
\hline Outcomes & $\begin{array}{l}\text { Primary: radiographs at } 6,12,18,26,38 \text { and } 52 \text { weeks } \\
\text { Secondary: rates of nonunion of tibial fractures }(6,12,18,26,38 \text { and } 52 \text { weeks) }\end{array}$ \\
\hline Starting date & $01 / 07 / 2005$ (estimated completion of recruitment 2012) \\
\hline Contact information & Dr Jason Busse, Toronto (j.busse@rogers.com) \\
\hline Notes & $\begin{array}{l}\text { This multi-centre study, involving centres in USA and Canada, is sponsored by Smith \& Nephew. It has the } \\
\text { same name as the other trial on conservatively treated tibia fractures }\end{array}$ \\
\hline
\end{tabular}


DATA AND ANALYSES

Comparison 1. LIPUS versus control

$\begin{array}{lcccc}\text { Outcome or subgroup title } & \begin{array}{c}\text { No. of } \\ \text { studies }\end{array} & \begin{array}{c}\text { No. of } \\ \text { participants }\end{array} & \text { Statistical method } & \text { Effect size }\end{array}$

\begin{tabular}{|c|c|c|c|c|}
\hline $\begin{array}{l}1 \text { Time to return to work complete } \\
\text { fractures (days) }\end{array}$ & 1 & & Mean Difference (IV, Fixed, 95\% CI) & Totals not selected \\
\hline $\begin{array}{l}1.1 \text { Resumption of work (as } \\
\text { reported) }\end{array}$ & 1 & & Mean Difference (IV, Fixed, 95\% CI) & $0.0[0.0,0.0]$ \\
\hline $\begin{array}{l}\text { 1.2 Resumption of work } \\
\text { (worst case scenario) }\end{array}$ & 1 & & Mean Difference (IV, Fixed, 95\% CI) & $0.0[0.0,0.0]$ \\
\hline $\begin{array}{l}2 \text { Time to return to training / duty } \\
\text { after stress fracture (days): as } \\
\text { reported analysis (days) }\end{array}$ & 2 & 93 & Mean Difference (IV, Random, 95\% CI) & $-8.55[-22.71,5.61]$ \\
\hline $\begin{array}{l}3 \text { Time to fracture radiographic } \\
\text { union (days): 'as reported' } \\
\text { analysis }\end{array}$ & 8 & 355 & Std. Mean Difference (IV, Random, 95\% CI) & $-0.69[-1.31,-0.07]$ \\
\hline 3.1 Upper limb & 3 & 183 & Std. Mean Difference (IV, Random, 95\% CI) & $-0.93[-2.03,0.17]$ \\
\hline 3.2 Lower limb & 5 & 172 & Std. Mean Difference (IV, Random, 95\% CI) & $-0.54[-1.44,0.35]$ \\
\hline $\begin{array}{l}4 \text { Time to fracture radiographic } \\
\text { union (days): worst case } \\
\text { analysis }\end{array}$ & 8 & 446 & Std. Mean Difference (IV, Random, 95\% CI) & $-0.47[-1.14,0.20]$ \\
\hline 4.1 Upper limb & 3 & 235 & Std. Mean Difference (IV, Random, 95\% CI) & $-0.66[-1.93,0.60]$ \\
\hline 4.2 Lower limb & 5 & 211 & Std. Mean Difference (IV, Random, 95\% CI) & $-0.35[-1.27,0.56]$ \\
\hline $\begin{array}{l}5 \text { Time to fracture union (days) } \\
\text { subgrouped by operation: worst } \\
\text { case analysis }\end{array}$ & 7 & 326 & Std. Mean Difference (IV, Random, 95\% CI) & $-0.62[-1.29,0.06]$ \\
\hline 5.1 Operatively treated & 4 & 114 & Std. Mean Difference (IV, Random, 95\% CI) & $-0.21[-1.42,1.00]$ \\
\hline 5.2 Conservatively treated & 3 & 212 & Std. Mean Difference (IV, Random, 95\% CI) & $-1.09[-1.38,-0.80]$ \\
\hline $\begin{array}{l}6 \text { Time to fracture union (days) } \\
\text { subgrouped by smoking status: } \\
\text { worst case analysis }\end{array}$ & 2 & 111 & Std. Mean Difference (IV, Random, 95\% CI) & $-1.06[-1.47,-0.65]$ \\
\hline 6.1 Smokers & 2 & 44 & Std. Mean Difference (IV, Random, 95\% CI) & $-1.17[-2.09,-0.25]$ \\
\hline 6.2 Non-smokers & 2 & 67 & Std. Mean Difference (IV, Random, 95\% CI) & $-1.06[-1.58,-0.53]$ \\
\hline $\begin{array}{l}7 \text { Delayed or non-union (as } \\
\text { reported analysis) }\end{array}$ & 8 & 333 & Risk Ratio (M-H, Random, 95\% CI) & $0.75[0.24,2.28]$ \\
\hline 7.1 Upper limb & 3 & 203 & Risk Ratio (M-H, Random, 95\% CI) & $0.0[0.0,0.0]$ \\
\hline 7.2 Lower limb & 5 & 130 & Risk Ratio (M-H, Random, 95\% CI) & $0.75[0.24,2.28]$ \\
\hline $\begin{array}{l}8 \text { Pain at } 8 \text { weeks (VAS: } 0 \text { no pain } \\
\text { to } 10 \text { worst pain) }\end{array}$ & 1 & & Mean Difference (IV, Fixed, 95\% CI) & Totals not selected \\
\hline 8.1 As reported analysis & 1 & & Mean Difference (IV, Fixed, 95\% CI) & $0.0[0.0,0.0]$ \\
\hline 8.2 Worst case analysis & 1 & & Mean Difference (IV, Fixed, 95\% CI) & $0.0[0.0,0.0]$ \\
\hline
\end{tabular}


Comparison 2. ECSW versus control

\begin{tabular}{|c|c|c|c|c|}
\hline Outcome or subgroup title & $\begin{array}{l}\text { No. of } \\
\text { studies }\end{array}$ & $\begin{array}{c}\text { No. of } \\
\text { participants }\end{array}$ & Statistical method & Effect size \\
\hline $\begin{array}{l}1 \text { Non-union at } 12 \text { months } \\
\text { follow-up }\end{array}$ & 1 & & Risk Ratio (M-H, Fixed, 95\% CI) & Totals not selected \\
\hline 1.1 As reported analysis & 1 & & Risk Ratio (M-H, Fixed, 95\% CI) & $0.0[0.0,0.0]$ \\
\hline 1.2 Sensitivity analysis & 1 & & Risk Ratio (M-H, Fixed, 95\% CI) & $0.0[0.0,0.0]$ \\
\hline $\begin{array}{l}2 \text { Pain at } 3 \text { months (VAS: } 0 \text { no } \\
\text { pain to } 10 \text { severe pain) }\end{array}$ & 1 & & Mean Difference (IV, Fixed, 95\% CI) & Totals not selected \\
\hline 2.1 As reported analysis & 1 & & Mean Difference (IV, Fixed, 95\% CI) & $0.0[0.0,0.0]$ \\
\hline 2.2 Worst case analysis & 1 & & Mean Difference (IV, Fixed, 95\% CI) & $0.0[0.0,0.0]$ \\
\hline
\end{tabular}

\section{Analysis I.I. Comparison I LIPUS versus control, Outcome I Time to return to work complete fractures (days).}

Review: Ultrasound and shockwave therapy for acute fractures in adults

Comparison: I LIPUS versus control

Outcome: I Time to return to work complete fractures (days)

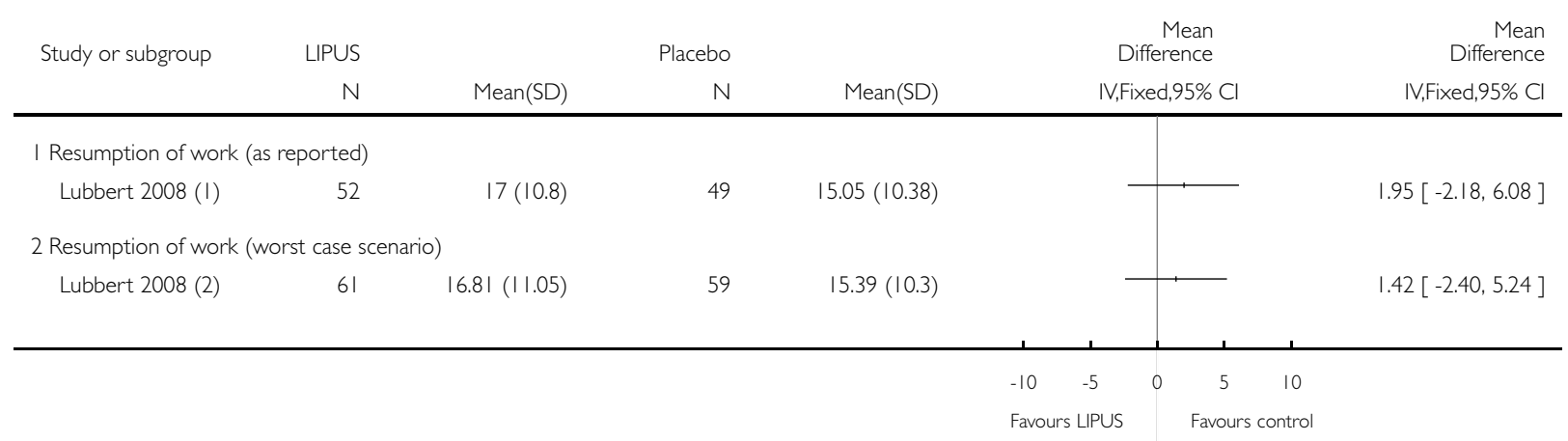

(I) Reported mean (published) SD confirmed (unpublished, author communication)

(2) Reported whole group (unpublished, author communication) 
Analysis I.2. Comparison I LIPUS versus control, Outcome 2 Time to return to training / duty after stress fracture (days): as reported analysis (days).

Review: Ultrasound and shockwave therapy for acute fractures in adults

Comparison: I LIPUS versus control

Outcome: 2 Time to return to training / duty after stress fracture (days): as reported analysis (days)

\begin{tabular}{|c|c|c|c|c|c|c|c|}
\hline \multirow[t]{2}{*}{ Study or subgroup } & \multirow{2}{*}{$\begin{array}{l}\text { LIPUS } \\
\mathrm{N}\end{array}$} & \multicolumn{3}{|c|}{ Control } & \multirow{2}{*}{$\begin{array}{c}\text { Mean } \\
\text { Difference } \\
\text { IV,Random,95\% Cl }\end{array}$} & \multirow[t]{2}{*}{ Weight } & $\begin{array}{r}\text { Mean } \\
\text { Difference }\end{array}$ \\
\hline & & Mean(SD) & $\mathrm{N}$ & Mean(SD) & & & IV,Random, $95 \% \mathrm{Cl}$ \\
\hline Rue 2004 (I) & 14 & $56.2(19.6)$ & 12 & $55.8(15.5)$ & 1 & $39.5 \%$ & $0.40[-13.10,13.90]$ \\
\hline Yadav 2008 (2) & 39 & $25.46(3.84)$ & 28 & $39.84(5.36)$ & + & $60.5 \%$ & $-14.38[-16.70,-12.06]$ \\
\hline
\end{tabular}

Total (95\% CI) 53

40

$100.0 \% \quad-8.55[-22.71,5.61]$

Heterogeneity: $\mathrm{Tau}^{2}=84.79 ; \mathrm{Chi}^{2}=4.47, \mathrm{df}=\mathrm{I}(\mathrm{P}=0.03) ; \mathrm{I}^{2}=78 \%$

Test for overall effect: $Z=1.18(P=0.24)$

Test for subgroup differences: Not applicable

(I) Reported mean and SD (published)

(2) Reported mean and SD (published) 
Analysis I.3. Comparison I LIPUS versus control, Outcome 3 Time to fracture radiographic union (days): 'as reported' analysis.

Review: Ultrasound and shockwave therapy for acute fractures in adults

Comparison: I LIPUS versus control

Outcome: 3 Time to fracture radiographic union (days): 'as reported' analysis

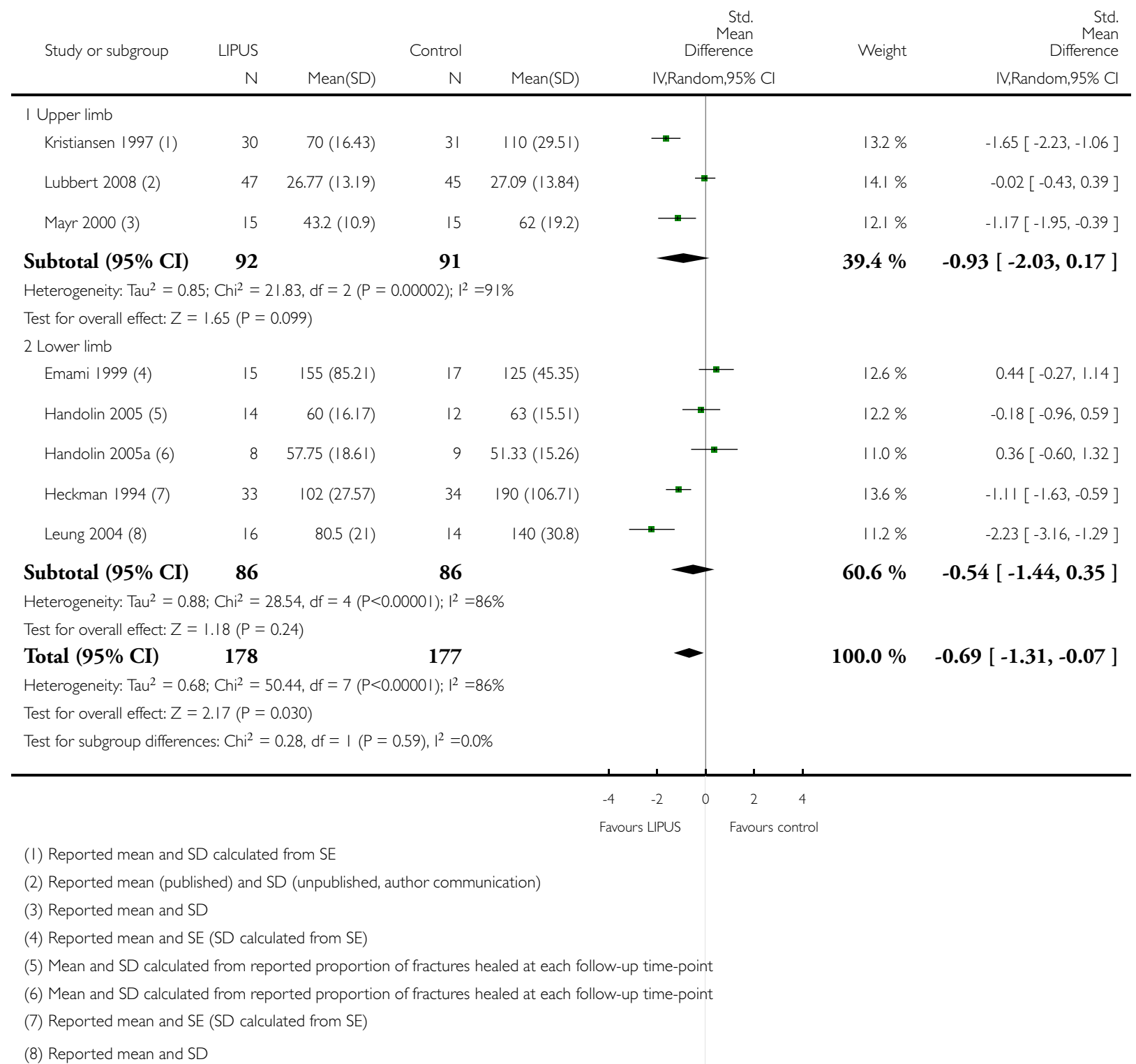


Analysis I.4. Comparison I LIPUS versus control, Outcome 4 Time to fracture radiographic union (days): worst case analysis.

Review: Ultrasound and shockwave therapy for acute fractures in adults

Comparison: I LIPUS versus control

Outcome: 4 Time to fracture radiographic union (days): worst case analysis

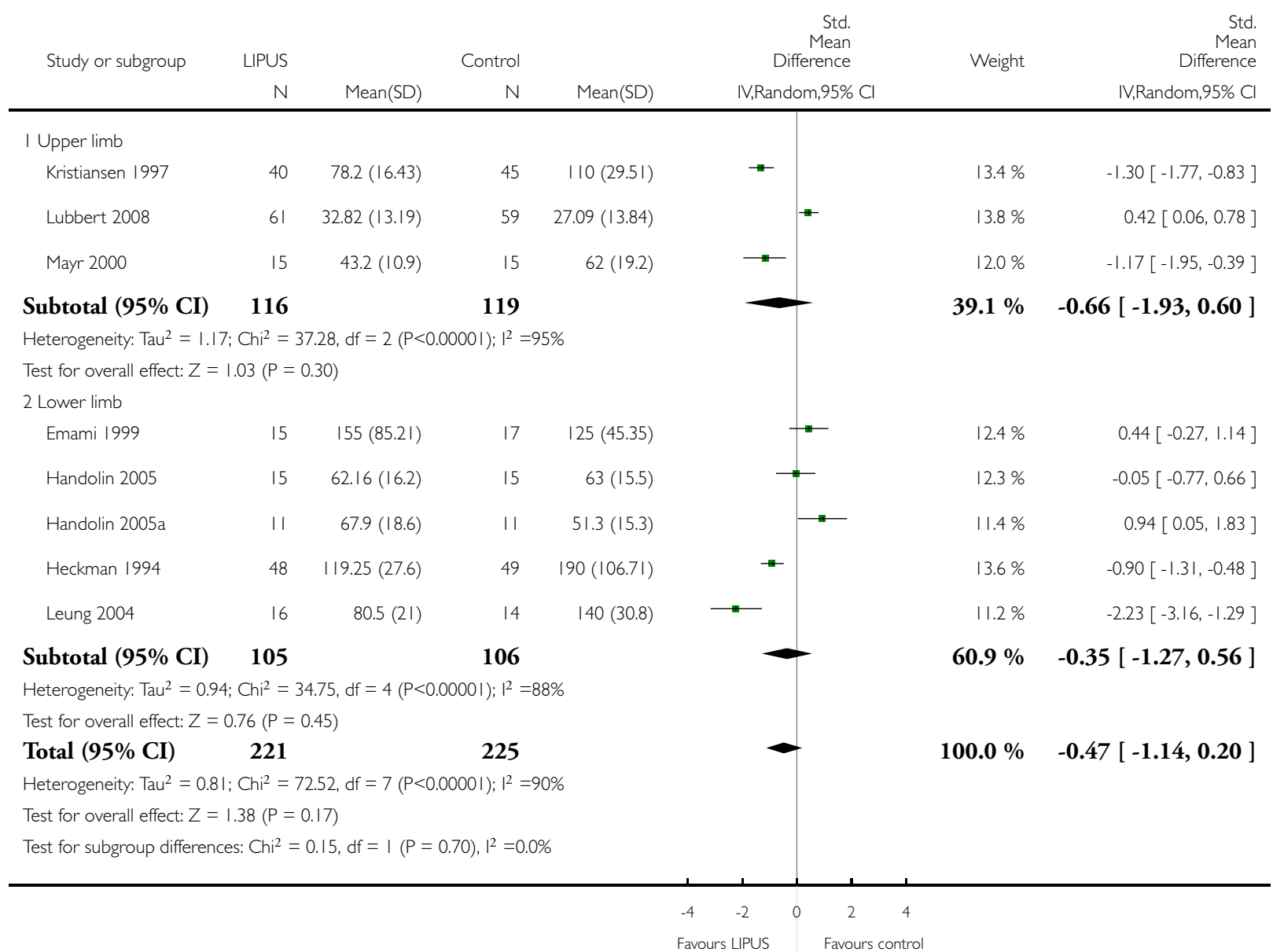


Analysis I.5. Comparison I LIPUS versus control, Outcome 5 Time to fracture union (days) subgrouped by operation: worst case analysis.

Review: Ultrasound and shockwave therapy for acute fractures in adults

Comparison: I LIPUS versus control

Outcome: 5 Time to fracture union (days) subgrouped by operation: worst case analysis

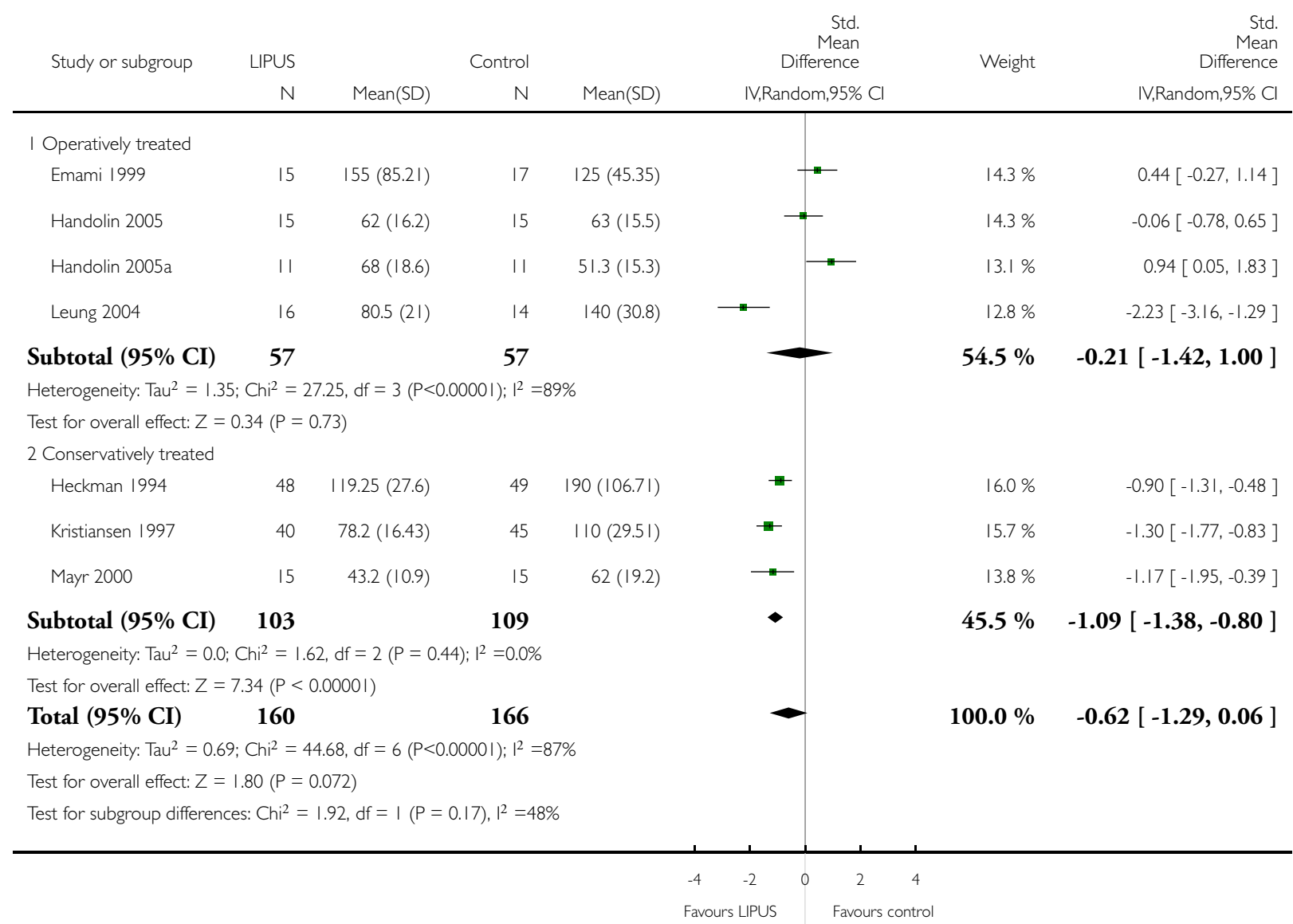


Analysis I.6. Comparison I LIPUS versus control, Outcome 6 Time to fracture union (days) subgrouped by smoking status: worst case analysis.

Review: Ultrasound and shockwave therapy for acute fractures in adults

Comparison: I LIPUS versus control

Outcome: 6 Time to fracture union (days) subgrouped by smoking status: worst case analysis

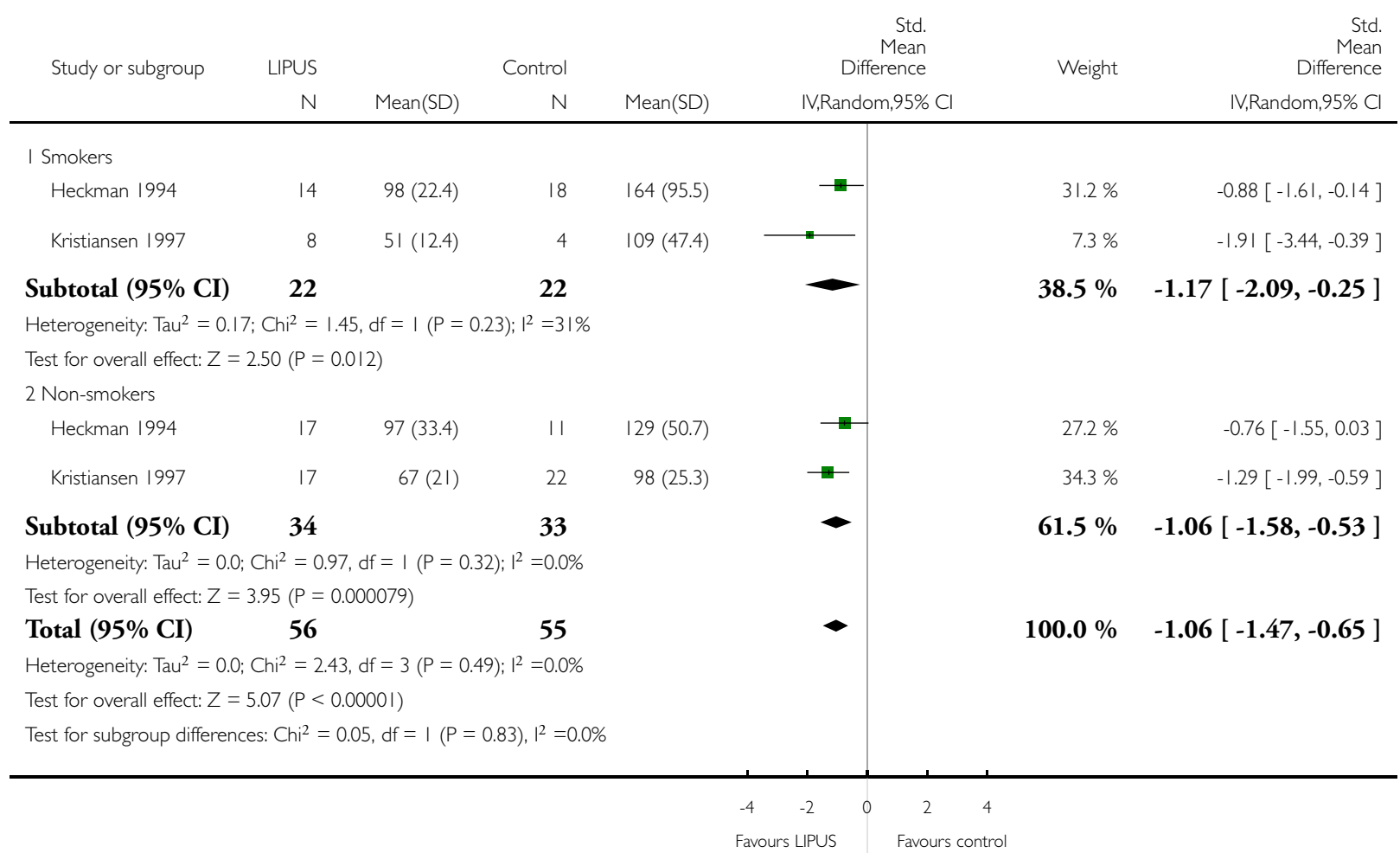




\section{Analysis I.7. Comparison I LIPUS versus control, Outcome 7 Delayed or non-union (as reported analysis).}

Review: Ultrasound and shockwave therapy for acute fractures in adults

Comparison: I LIPUS versus control

Outcome: 7 Delayed or non-union (as reported analysis)

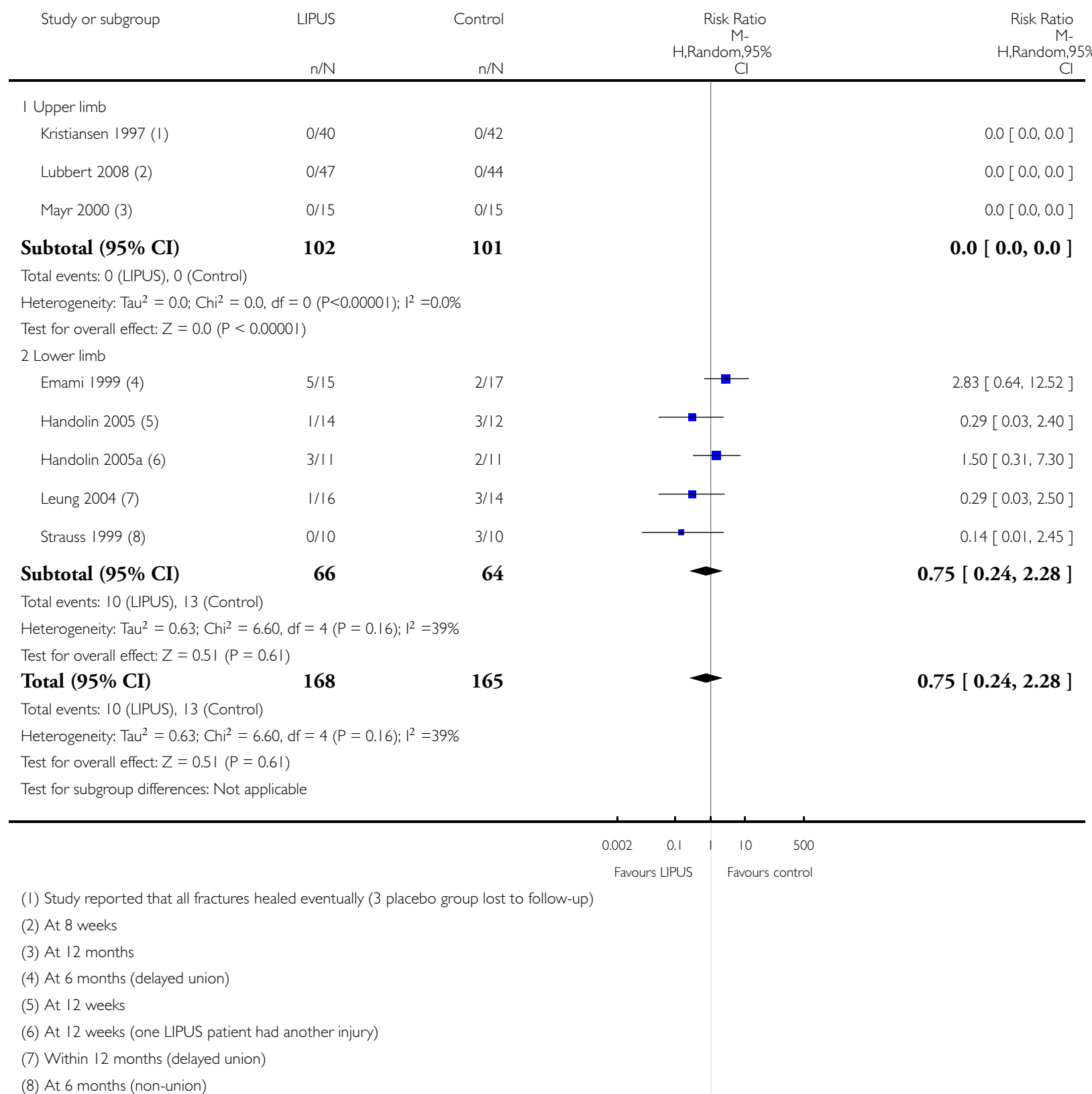


Analysis I.8. Comparison I LIPUS versus control, Outcome 8 Pain at 8 weeks (VAS: 0 no pain to 10 worst pain).

Review: Ultrasound and shockwave therapy for acute fractures in adults

Comparison: I LIPUS versus control

Outcome: 8 Pain at 8 weeks (VAS: 0 no pain to 10 worst pain)

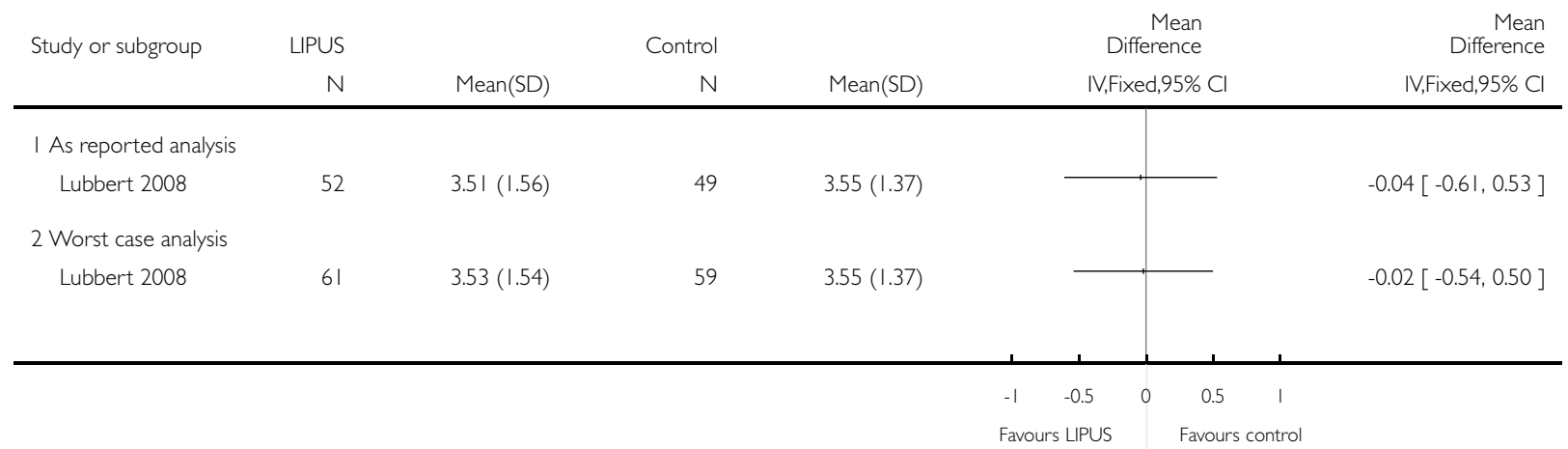

\section{Analysis 2.I. Comparison 2 ECSW versus control, Outcome I Non-union at 12 months follow-up.}

Review: Ultrasound and shockwave therapy for acute fractures in adults

Comparison: $2 \mathrm{ECSW}$ versus control

Outcome: I Non-union at 12 months follow-up

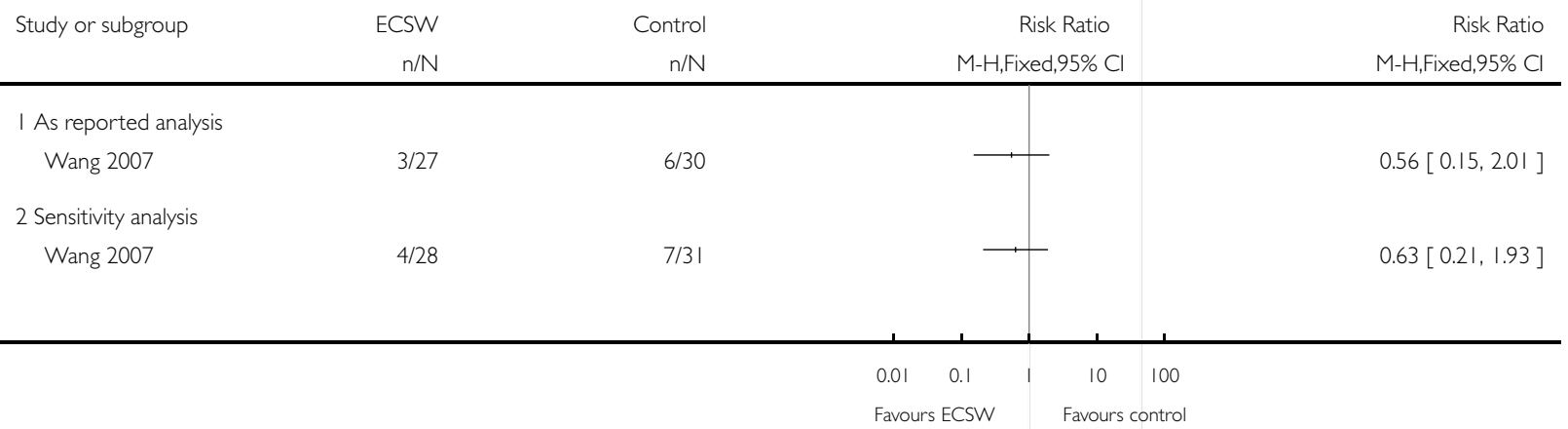


Analysis 2.2. Comparison 2 ECSW versus control, Outcome 2 Pain at 3 months (VAS: 0 no pain to 10 severe pain).

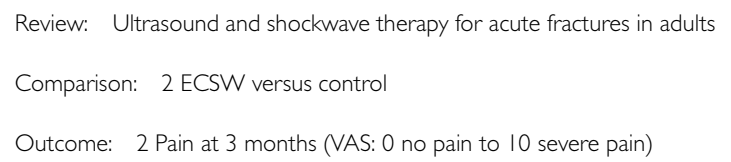

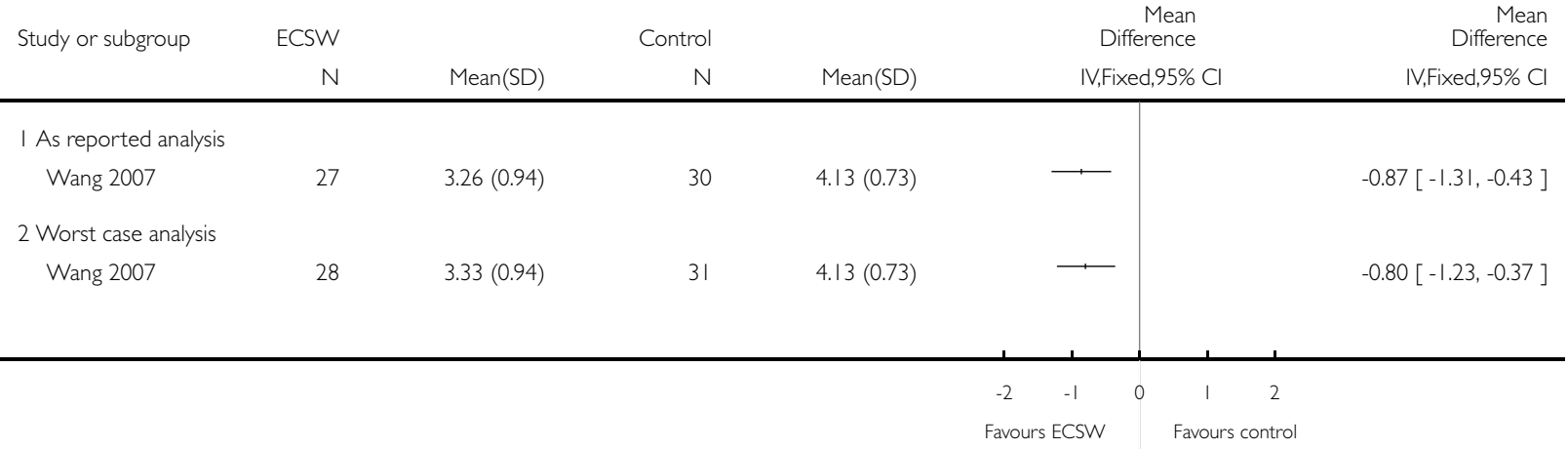

\section{A P P E N D I C E S}

\section{Appendix I. Search strategies}

\section{The Cochrane Central Register of Controlled Trials (Wiley)}

\#1 MeSH descriptor Ultrasonics, this term only

\#2 MeSH descriptor Ultrasonic Therapy, this term only

\#3 MeSH descriptor High-Energy Shock Waves, this term only

\#4 (ultraso* or LIPUS or shock wave* or shockwave* or ESWT):ti,ab

\#5 (\#1 OR \#2 OR \#3 OR \#4)

\#6 MeSH descriptor Fractures, Bone explode all trees

\#7 MeSH descriptor Fracture Healing, this term only

\#8 MeSH descriptor Bone Remodeling explode all trees

\#9 MeSH descriptor Bony Callus, this term only

$\# 10$ fractur*:ti,ab

\#11 (\#6 OR \#7 OR \#8 OR \#9 OR \#10)

\#12 (\#5 AND \#11) 


\section{MEDLINE (OvidSP interface)}

1. Ultrasonics/ or Ultrasonic Therapy/ or High-Energy Shock Waves/

2. (ultraso $\$$ or LIPUS or HIPUS or shock wave\$ or shockwave\$ or ESWT).tw.

3. or/1-2

4. exp Fractures, Bone/ or Fracture Healing/ or exp Bone Remodeling/ or Bony Callus/

5. fractur $\$ . t w$

6. or/ $4-5$

7. and $/ 3,6$

8. (dental or tooth or oral).mp.

9. 7 not 8

10. Randomized Controlled Trial.pt.

11. Controlled Clinical Trial.pt.

12. randomized.ab.

13. placebo.ab.

14. Drug Therapy.fs.

15. randomly.ab.

16. trial.ab.

17. groups.ab.

18. or/10-17

19. exp Animals/ not Humans/

20. 18 not 19

21. and $/ 9,20$

\section{EMBASE (OvidSP interface)}

1. Ultrasound/ or Ultrasound Therapy/ or Low Intensity Pulsed Ultrasound/ or Extracorporeal Lithotripsy/

2. (ultraso\$ or LIPUS or shock wave\$ or shockwave\$ or ESWT).tw.

3. or/1-2

4. exp Fracture/ or Fracture Treatment/ or Bone Remodeling/

5. fractur\$.tw.

6. or $/ 4-5$

7. and $/ 3,6$

8. (dental or tooth or oral).mp.

9. 7 not 8

10. Clinical trial/

11. Randomized Controlled Trial/

12. Randomization/

13. Single Blind Procedure/

14. Double Blind Procedure/

15. Crossover Procedure/

16. Placebo/

17. Randomi?ed controlled trial\$.tw.

18. Rct.tw.

19. Random allocation.tw.

20. Randomly allocated.tw.

21. Allocated randomly.tw.

22. (allocated adj2 random).tw.

23. Single blind\$.tw.

24. Double blind $\$$.tw.

25. ((treble or triple) adj blind $\$)$.tw.

26. Placebo\$.tw.

27. Prospective Study/

28. or/10-27 
29. Case Study/

30. Case report.tw.

31. Abstract Report/ or Letter/

32. or $/ 29-31$

33.28 not 32

34. limit 33 to Human

35. and $/ 9,34$

\section{H I S T O R Y}

Protocol first published: Issue 7, 2010

Review first published: Issue 2, 2012

\section{CONTRIBUTIONS OFAUTHORS}

XL Griffin is responsible for the conception, design and writing of the review. He is the co-guarantor of the review.

ML Costa is involved in conception and design of the review. He is the co-guarantor of the review.

$\mathrm{N}$ Parsons is the review statistician. He is responsible for the data management and analysis plan.

$\mathrm{N}$ Smith is responsible for study retrieval strategy and writing the review.

\section{DECLARATIONSOF INTEREST}

None known.

\section{SOURCES OF SUPPORT}

\section{Internal sources}

- University Hospital Coventry and Warwickshire NHS Trust, UK. Provision of salary to NS

- University of Warwick, UK.

Provision of salaries to NP and MC

\section{External sources}

- Furlong Charitable Research Foundation, UK. Provision of salary to XG through a PhD fellowship. 


\section{DIFFERENCES BETWEEN PROTOCOLANDREVIEW}

\section{Data analysis}

We anticipated that the primary analysis in the included studies was likely to be a survival analysis using the time to fracture union as the outcome measure. Therefore, it seemed likely that the majority of studies would report either log-rank statistics or estimates of hazard ratios, after fitting Cox's proportional hazards regression model, as an estimate of the intervention effect. However, the majority of studies reported mean healing times. We specified that we would deal with such continuous data by estimating the mean differences and $95 \%$ confidence intervals. Since the included studies report outcomes from participants with a variety of long bone injuries, which are well understood to have widely varying healing times normally, we chose to combine these data using standardised mean differences.

\section{Dealing with missing data}

We altered our method of dealing with missing continuous data where these remained unavailable after attempting to contact trial authors. In order to determine a conservative estimate of any treatment effect, we assumed that the missing data from participants in the treatment group lay at the extreme of the distribution (2 SD from the reported mean). Conversely, for participants in the control group we assumed the distribution was unaffected by the missing data.

\section{Sensitivity analyses}

We anticipated that outcomes may have been reported at a number of time points (e.g. six months and twelve months). We planned to include these outcomes in order to provide some sensitivity to the selection of an appropriate follow-up time for assessment of the treatment effect. Given these data were not available, such an analysis was not necessary. 